\title{
Las salvadoreñas, las primeras latinoamericanas que votaron. 1921
}

\section{Héctor Lindo Fordham University}

Resumen: Esta exploración del feminismo temprano en El Salvador describe el entorno social en el que, desde finales del siglo XIX, las mujeres salvadoreñas comenzaron a organizarse y a incidir en la vida política salvadoreña para reclamar su derecho a participar como ciudadanas con derecho a voto. Al estudiar la creciente participación de las mujeres en el mundo laboral urbano y su involucramiento en las nuevas formas de sociabilidad de la época, la investigación muestra que el feminismo temprano en El Salvador tenía una base social amplia. El estudio muestra que figuras icónicas como Prudencia Ayala no trabajaban de forma aislada. Numerosas costureras, vendedoras de los mercados, maestras, tipógrafas y mujeres de la élite organizaban asociaciones, escribían artículos, asistían a manifestaciones y presionaban a los políticos para lograr sus objetivos. La causa del unionismo fue un vehículo para que numerosos grupos de mujeres participaran en la vida política y promovieran lo que fue su logro más importante: la incorporación del sufragio femenino a la Constitución federal de 1921 y el ejercicio del sufragio en las elecciones de octubre de ese año.

Palabras claves: Feminismo, unionismo, movimientos sociales, sufragio femenino, Prudencia Ayala

Abstract: This exploration of early feminism in El Salvador describes the social environment since the late 19th century in which Salvadoran women began to organize and influence Salvadoran political life to claim their right to participate as citizens with the right to vote. By studying the increasing participation of women in urban workplaces and their involvement in the new forms of sociability of the time, the research shows that early feminism in El Salvador had a broad social base. The study shows that iconic figures like Prudencia Ayala did not work in isolation. Numerous seamstresses, market vendors, teachers, typographers, and elite women organized associations, wrote articles, attended demonstrations and lobbied politicians to achieve their goals. The cause of unionism was a vehicle for numerous groups of women to participate in political life and promote what was 
their most important achievement: the incorporation of female suffrage into the federal Constitution of 1921 and the exercise of suffrage in the October elections of that year.

Keywords: Feminism, unionism, social movements, women's suffrage, Prudencia Ayala.

\begin{abstract}
"[C]uando la mujer se propone algo benéfico y grandioso, no hay nada que resista a su empuje. Los hombres, como dignos compañeros de ella, habrán de disputarse el honor de secundarla y sostenerla".

Delfina Lagos, organizadora del “Comité Unionista de Señoras y Señoritas de Ahuachapán”, 1917
\end{abstract}

\title{
Introducción
}

Conocemos pocos nombres propios. Los recuentos de la época se refieren a ellas como "mujeres santanecas". Pero estaban ahí, en El Molino, a la entrada de Coatepeque, agazapándose detrás de los árboles de la montaña, disparando sus armas de fuego, luchando hombro a hombro con las tropas de los generales Joaquín Pérez y Tomás Regalado. Un soleado día de mayo de 1894 trataron de resistir sin éxito al "León de la Frontera”, Antonio Ezeta, y sus 2,500 hombres. Ellas, que sintieron el llamado a unirse a la revuelta contra la tiranía del presidente Carlos Ezeta y su hermano Antonio, lucharon con osadía en el campo de batalla. El general Regalado premió a varias con rangos militares (Ejército de $\mathrm{El}$ Salvador, 1894).
La batalla de El Molino terminó en derrota, pero fue un revés temporal. Después de un duro mes de lucha, los hermanos Ezeta salieron al exilio y llegó al poder el general Rafael Antonio Gutiérrez. Los libros de historia recuerdan con admiración a los 44 hombres que se pronunciaron contra los Ezeta. "Los nombres de los 44 inmortales brillan con resplandor de astros de primera magnitud en el cenit del cielo centro-americano" decía el Boletín del Ejército de 1894 (Ejército de $\mathrm{El}$ Salvador, 1894, p. 5). En las páginas de la narrativa oficial se vislumbra a regañadientes la presencia de algunas de las valerosas que ayudaron en la empresa. El Boletín, que enunció para la posteridad los nombres y las hazañas de "los 44", dedica unos cuantos párrafos desperdigados al "arrojo excesivo 
que nuestras mujeres presentan en los campamentos [...] sublimes heroínas sin nombre" (Ejército de El Salvador, 1894, p. 17).

Aunque sus nombres no aparezcan en monumentos, estas mujeres dejaron huella. Aurelia, una de las heroínas de la batalla de El Molino, era la madre de Prudencia Ayala. Durante su infancia, Prudencia escuchaba a las amigas de su madre relatar las hazañas de 1894 mientras tomaban café (Ayala, 1928). ${ }^{1}$ La biografía del ícono del feminismo temprano en El Salvador se entrelaza con las historias de muchas mujeres borradas de la historia. Ellas conquistaron una victoria prácticamente desconocida de las mujeres salvadoreñas. Antes que cualquier otra latinoamericana, la actividad política de las salvadoreñas logró que las leyes reconocieran su derecho a votar. Triunfantes, muchas se presentaron a las urnas electorales a finales de 1921. Nadie recuerda esta proeza.

El artículo cuenta esta historia tomando como punto de partida un hito histórico en la vida republicana del país: las reformas liberales a partir de la década de 1870. La apertura del país al comercio y a influencias externas, la secularización y la centralización del sistema escolar crearon un espacio para la discusión de la educación de la mujer y su participación ciudadana. Parte de la discusión fue entre intelectuales de la élite, pero también hay que tomar en cuenta las acciones de pioneras como Aurelia Ayala que irrumpieron de diversas maneras en el espacio público. Estos temas se cubren en la primera sección. La segunda parte describe el contexto social en el que se desenvolvieron las activistas políticas que impulsaron el proyecto del sufragio femenino. Se trata de una sociedad que se urbanizaba, donde empezaron a crearse oportunidades para preparar a las mujeres para el mundo laboral y en el que ellas aprovecharon el impulso asociativo imperante. La siguiente sección describe la coyuntura política del unionismo que las mujeres salvadoreñas aprovecharon brillantemente para posicionarse en la vida política del país y lograr el derecho al sufragio. El artículo termina con las circunstancias que rodearon la inclusión del sufragio femenino en la Constitución Política de la República Federal de Centroamérica de 1921 y el momento en que votaron las mujeres.

\section{Mujer y ciudadanía}

Las mujeres aumentaron su participación en la esfera pública en la segunda mitad del siglo XIX. A la vez que se consolidaba el Estado salvadoreño después de la ruptura de la Federación, la economía se 
reorientaba hacia las exportaciones y una nueva generación de liberales con una agenda de secularización, inspirados en el positivismo, determinados a imponer "orden y progreso", tomaba las riendas. El papel de la mujer en la cosa pública fue tema de reflexión y debate (Vásquez Monzón y Tamayo-Acosta, 2014)

De acuerdo con Olga Vásquez, la discusión del papel de las mujeres como ciudadanas arranca en $\mathrm{El}$ Salvador con el debate paralelo sobre su educación y la laicización del Estado. Alrededor de la década de 1880, los intelectuales liberales incorporaron a su discurso la importancia de la educación de la mujer, su ciudadanía y el derecho al sufragio. Para 1880 , al discutir el programa de estudios de las escuelas de maestras, un editorialista hablaba de la posibilidad de que las mujeres siguieran estudios avanzados (Vásquez Monzón, 2013, pp. 15-16). El Estado organizó "colegios de señoritas", y la primera versión del Colegio Normal de Señoritas. Esta institución ayudó a que la enseñanza se convirtiera en uno de los principales vehículos de inserción de las mujeres en el mundo laboral urbano fuera de la esfera del hogar. ${ }^{2}$ "Algunos intelectuales" dice Vásquez, "comenzaron a perfilar la ciudadanía femenina como consecuencia lógica del proceso de instrucción intelectual de las mujeres" (Vásquez Monzón, 2013, p. 22). ${ }^{3}$

Esta conversación desembocó en el tema de la participación de la mujer como ciudadana con la posibilidad de votar. En 1881, en la ceremonia de apertura del año lectivo de la Universidad Central de El Salvador, un ingeniero, el Licenciado Pedro García, abogó a favor de que la mujer fuera ciudadana con derecho al voto. Sus palabras fueron: "hagamos una mujer inteligente, una mujer ciudadana que hable, que escriba, que vote y enseñe sus hijos a bendecir el dulce nombre de la patria”.

El licenciado García hablaba en tiempos de inestabilidad política, en los que era evidente la voluntad de las mujeres de hacer escuchar su voz en los asuntos nacionales. Los liberales que apoyaban a Francisco Menéndez derrocaron al gobierno de Rafael Zaldívar en lo que los contemporáneos llamaron la "revolución de 1885". A pesar de la costumbre decimonónica de invisibilizar a las mujeres de las narrativas políticas, un reportaje de la época nos da indicios de un protagonismo femenino considerable:

\section{(...) tenemos que reconocer el civismo de los San Salvadoreños, especialmente el muy caracterizado de que las señoras de la capital han dado pruebas en esta ocasión. Ellas con su natural}


y nunca disputada influencia han contribuido por su parte al desenlace satisfactorio de la contienda que acaba de pasar, y ellas fueron las que á la primera noticia de la aproximación del ejército libertador á la capital, se aprestaron á recibirlo cual correspondía, preparando especialmente las coronas con que ellas, intérpretes en esta ocasión de la justicia, han querido premiar el valor y el patriotismo. Honor al bello sexo de San Salvador. La revolución de 1885, verdaderamente popular, ha tenido también en su favor la opinión, el aplauso y el entusiasmo de la mujer, que no es ni debe ser en manera alguna extraña a la suerte de la patria. iQue esa revolución logre en el campo de la paz las aspiraciones del patriotismo! ("El Triunfo de la revolución en Salvador", p. 332.

Francisco Menéndez y sus salvadoreñas aliadas a la jerarquía seguidores buscaron plasmar sus de la Iglesia Católica alzó la voz ideales de un régimen liberal con para solicitar a los diputados de la un Estado laico en la Constitución Asamblea que abandonaran las ideas de 1886. Irónicamente, el de separación entre iglesia y Estado debate sobre el Estado laico y la que querían incluir en la Carta Magna. participación política en la Asamblea Constituyente abrió oportunidades para que mujeres que defendían el estatus quo manifestaran con vigor sus puntos de vista. Un grupo de

En su carta hablan con voz poderosa para defender el mismo orden legal que las mantenía circunscritas a la esfera doméstica:

No extrañéis, Honorable Congreso, que el débil sexo, dejando el recinto doméstico donde cumple constantemente sus deberes, se presente hoy en la zona más alta del Poder público que discute los asuntos más importantes de la Patria. No le traen aquí la política ni los partidos, ni ambición de ninguna clase, ni interés alguno que le sea ageno: el amor á su religión, la paz de su hogar, la santidad de su matrimonio, los derechos de su maternidad, el porvenir de sus hijos, gravemente amenazados por ese proyecto, son los irresistibles estímulos que le traen ante el Poder encargado de garantizar los derechos naturales del individuo en el estado social. (Citado en Valdés Valle, 2010, p. 71). 
Algunos liberales usaron este tipo de activismo como excusa para oponer la participación de las mujeres en política por considerarlas instrumentos del clero. Pero había otro aspecto del activismo de las católicas amigas de la jerarquía eclesiástica que resultaba atractivo para el proyecto liberal. Ellas podían ser aliadas en la creación de instituciones para avanzar políticas sociales dentro de un proyecto de higiene social. ${ }^{4}$ Sara Guerra de Zaldívar, la esposa del presidente Rafael Zaldívar (1876-1885), es el ejemplo más importante de una católica conservadora de la élite que desempeñó un papel crucial en la organización de instituciones filantrópicas dentro del modelo liberal. Desde 1876, cuando su intervención fue decisiva para la fundación del Hospicio de Huérfanos, hasta su muerte en 1911, doña Sara impulsó la introducción de la Cruz Roja, una escuela de artes y oficios para mujeres pobres, la Sala Cuna, el Dispensario Médico-Quirúrgico y el Asilo de Ancianos que lleva su nombre. ${ }^{5}$

En las zonas rurales también podemos encontrar ejemplos de mujeres prestas a hacer escuchar su voz. Patricia Alvarenga relata en su trabajo el caso del enfrentamiento entre Inés Perdido y el comisionado cantonal Julián Argueta en 1885. Si el comisionado albergaba el sueño patriarcal de mujeres sumisas y tímidas se llevó una gran sorpresa con Inés. Cuando Argueta llegó a su casa ella lo recibió con una avalancha épica de insultos. Los legajos del proceso legal que siguió a la visita del comisionado registran la actitud de constante desafío de Inés (Alvarenga, 1996, p. 183).

En este mundo finisecular encontramos a una pionera, una joven llamada Antonia Navarro, que aprovechó la pequeña apertura que mostraron algunos intelectuales en el entorno universitario. En 1887 se inscribió en la escuela de ingeniería donde llegó a graduarse. Desafortunadamente su prematura muerte en 1891 no le permitió dejar un legado como profesional o mentora de una nueva generación. Sin embargo, su éxito muestra una cierta anuencia en círculos intelectuales a la educación universitaria de la mujer. Algunas publicaciones de la época resaltaron su logro. Cinco años después de la muerte de la joven profesional, la revista El Porvenir de Centroamérica publicó su foto con un brevísimo perfil biográfico que resaltaba que "coronó su carrera de doctora en esa facultad [de ingeniería] con mucho mérito y grandes honores [...] su muerte fue muy sentida y las ciencias perdieron con ella una de sus más adictas y constantes admiradoras" (“Antonia Navarro", p. 388).

La iniciativa y valentía moral que demostró esta mujer de los grupos medios urbanos (el padre de Navarro 
era boticario) tuvo su contraparte militante durante el episodio de la revuelta de 1894 que se menciona en la introducción. Los informes militares de la época dan testimonio de la variedad de formas en que las mujeres participaron en la lucha contra los ejércitos de Antonio y Carlos Ezeta.

Los vencedores en el conflicto publicaron un número especial del Boletín del Ejército para dar a conocer al pueblo su versión de los hechos. El Boletín, además de dar un aura de heroísmo a sus autores, dedica algún espacio a comentar sobre "el arrojo excesivo que nuestras mujeres presentan en los campamentos. En lo más crudo del combate, cuando la muerte siembra el estrago cortando vidas, pero dando ejecutorias para la inmortalidad, las mujeres, sublimes heroínas sin nombre, penetran hasta el centro de la refriega a llevar auxilios a los que se baten, infundiendo el más alto valor a los soldados" (Ejército de El Salvador, 1894 , p. 17). "Hasta las mujeres toman el fusil" manifestaba el Boletín. La única luchadora que el texto menciona con nombre propio es Petrona Villeda quién "con su arrojo e intrepidez electrizaba a los soldados que viendo en medio de ellos una mujer de tales brillos, se lanzaban con nuevos ímpetus a la batalla. Mujeres como Petrona Villeda son indispensables en los momentos del fuego" (Ejército de El Salvador, 1894, pp. 32, 35).
Más adelante aparecieron en la prensa referencias esporádicas que confirman el involucramiento de mujeres en el movimiento contra Ezeta. En 1912 el Diario del Salvador daba la noticia de la muerte de Isabel Carranza Monterrosa "quien en la revolución de 1894, que Santa Ana sostuvo hasta derrocar la tiranía de los Ezeta, peleó como el hombre más aguerrido en las diferentes acciones de armas que entonces se libraron, alcanzando el grado de capitana del ejército de la República". Sus funerales incluyeron la presencia de una banda de guerra y los honores de una compañía del ejército ("Una capitana del ejército salvadoreño. Peleó valientemente en 1894", p. 1).

A pesar de las noticias esporádicas, la memoria oficial de la revolución de "los 44" (todos hombres) y de la "ciudad heroica" de Santa Ana relegó al olvido a esas combatientes que tan importantes fueron en el triunfo contra los Ezeta. ¿Quién recuerda ahora a Petrona Villeda y a Isabel Carranza Monterrosa? Hubo una persona que aludía en sus escritos a las luchadoras santanecas y que las tomó como inspiración. Prudencia Ayala, en sus memorias, menciona cómo parte de su identidad el hecho de que era hija de la "coronela Aurelia Ayala" que había recibido rango militar por su bravura en 1894 .

En las conversaciones familiares la madre de Prudencia ratificaba la popularidad del régimen liberal 
democrático de Menéndez con las mujeres. Ella contaba que "Los Ezetas fueron traidores del presidente general Francisco Menéndez, gobernante honrado. Los Ezetas no habían de haberse portado mal con él, en fin ellos tiranizaron al pueblo salvadoreño" (Ayala, 1928, p. 86). La casa de las Ayala recibía visitas de las antiguas compañeras de batalla de Aurelia. "Llegaban a visitarla ya una, ya otra de las que componían el reducto femenino y se decían '¿recuerdas Aurelia de los días amargos que pasamos oyendo el ruido infernal de los cañones y fusiles y lamento de los heridos?"”. Las amigas de Aurelia incluían a Lola Soliz, la negra Macaria, Teresa Santa María, Ricarda Interiano y Anita Álvarez que habían luchado en las batallas de El Molino y el Portezuelo. Prudencia recuerda la respuesta de su madre cuando le preguntó si no había tenido temor durante la batalla: "Algún día comprenderás lo que es una buena opinión o un sentimiento en defensa de una buena causa en pro de los intereses del bien general de un pueblo." (Ayala, 1928, pp. 84-87). Y así fue. Las memorias de las hazañas de su madre estuvieron presentes en primera línea cuando Prudencia se lanzó a la aventura más importante de su vida, la campaña presidencial de 1930. En esa ocasión concedió una breve entrevista al periódico Patria en el que mencionó la disponibilidad de las mujeres de luchar por la patria en momentos de peligro y continuó diciendo "mi madre se batió en Santa Ana contra los Ezetas y se le dio el grado honorífico de coronel. Como ése, abundan los casos en nuestra historia" ("Prudencia Ayala defiende una causa justa y noble, cual es el derecho de la mujer a ser elector y ocupar altos puestos", p. 1) El recuerdo de mujeres que habían tomado las armas para defender sus derechos y luchar contra una tiranía acompañó a Prudencia Ayala durante toda su vida política.

A las disrupciones de mujeres como Antonia Navarro, Inés Perdido, Aurelia Ayala, Lola Soliz y sus amigas se puede añadir liderazgo femenino transgresor en las esferas sociales más altas. Victoria Magaña de Fortín presidía una familia con gran prestigio social en el departamento de Santa Ana. Su esposo, el próspero abogado de origen hondureño Miguel Fortín, fue entre otras cosas encargado de negocios y cónsul de El Salvador en Guatemala y presidente del Ateneo de El Salvador. Sus descendientes todavía se destacan en la vida social y política del país. En sus ratos libres, ella escribía artículos feministas que publicaba en La Prensa de Santa Ana bajo el seudónimo de Olimpia. Para 1902, ya tenía suficientes publicaciones para recopilarlas e imprimirlas en forma de libro. Sus artículos demuestran que se informaba regularmente de los movimientos feministas en Europa y estaba al tanto de las discusiones políticas sobre la 
ciudadanía de la mujer.7 En uno de sus trabajos habla del congreso socialista en Bruselas de 1891 en el que se que hizo un llamado a todos los países para la "afirmación enérgica en sus programas de la igualdad completa para ambos sexos: a que pida se otorguen a la mujer los mismos derechos civiles y políticos que al hombre" (Magaña de Fortín 1910, p. 35). Es decir, esta mujer de la élite leía periódicos europeos sin importar la orientación ideológica buscando argumentos para promover la participación política de la mujer.

Olimpia no trabajó en total aislamiento ni fue víctima del ostracismo social. La recopilación de artículos que publicó en 1902 fue iniciativa de su esposo, quien admiraba su trabajo intelectual y su actitud luchadora. En 1910, don Miguel Fortín dedicó a su esposa un poema en el que la anima a seguir lidiando por la igualdad de la mujer: "Adelante! A luchar! Nada de miedo/Hasta obtener de la igualdad la palma" (Magaña de Fortín 1910, p. 269). Olimpia recibía el reconocimiento de algunos intelectuales prominentes en el medio. El conocido positivista, don Santiago Barberena, escribió que le correspondía a ella "ponerse al frente del movimiento feminista de Centro América" (Magaña de Fortín 1910, p. 16). En el informe de la exposición nacional de 1904, su organizador, David J. Guzmán recomendaba "sobre todo los artículos literarios sobre la mujer de doña Victoria de Fortín (Olimpia)" (Moncada 1907, Anexos xxiv).

Posiblemente una mujer de la élite como doña Victoria tenía acceso fácil a la prensa extranjera, pero aun aquellas que no se podían dar ese lujo tenían acceso a información sobre los movimientos feministas en Europa y Estados Unidos. Periódicos locales como el Repertorio del Diario del Salvador (una revista quincenal vinculada al Diario del Salvador) y la Revista de la Enseñanza divulgaban artículos de precursoras del feminismo como la española Carmen de Burgos Seguí, la cubana Aurelia Castillo de González y noticias sobre las actividades de las sufragettes en Londres y Nueva York (Burgos Seguí, 1 de octubre de 1906, p. 201, y 1 de diciembre de 1906, p. 2183). Publicaciones como el Diario del Salvador imprimían artículos, con frecuencia anónimos, que abogaban por la igualdad de sexos ("La mujer colaboradora, no esclava", p.2). Además, durante la Primera Guerra Mundial las mujeres en Europa y Estados Unidos se incorporaron al mundo del trabajo y aumentaron su participación de forma sin precedentes. Las noticias sobre estas transformaciones sociales llegaban a El Salvador y deben de haber servido de inspiración para las lectoras locales. $^{9}$ 
Los ejemplos anteriores muestran la existencia temprana de un contexto político y social en el que se observaban retoños de un movimiento feminista, pero eran eso, retoños. El Salvador no ofrecía un ambiente de gran apertura para la participación de la mujer. Pero poco a poco, a todo nivel social, había grupos donde maduraban las ideas sobre la igualdad de sexos y la importancia de la ciudadanía plena para la mujer.

\section{Mujeres trabajadoras y nuevos espacios de sociabilidad}

El creciente interés de las mujeres en la participación política como ciudadanas se daba a la par de un cierto crecimiento de los espacios urbanos, con el cual aumentaba su número en el mundo laboral de las ciudades, aparecían nuevos espacios de sociabilidad y se ensanchaba la esfera pública. ${ }^{10}$

En El Salvador, al igual que en otros países latinoamericanos, la creciente feminización del magisterio creó oportunidades para que muchas educadoras, a quienes se entregaba explícitamente la tarea de "formar ciudadanos", buscaran la ciudadanía plena para ellas mismas y se unieran a movimientos feministas. ${ }^{11}$ En esta área, convergieron el trabajo fuera del hogar, un sentido de pertenencia e identidad profesional y la búsqueda de igualdad y derechos ciudadanos.

La feminización del magisterio comenzó en la segunda mitad del siglo XIX y, para finales de siglo, el número de mujeres que habían entrado al mundo laboral trabajando como maestras aumentó considerablemente. Con la centralización del sistema escolar durante los gobiernos liberales, también se dieron pasos para la profesionalización del magisterio. Uno de los hitos en este proceso fue el Primer Congreso Pedagógico Centroamericano que se celebró en Guatemala en 1893. La delegación salvadoreña al evento incluyó al subsecretario de instrucción pública don Nicolás Aguilar. Las discusiones de la reunión de pedagogos incluyeron nueve temas, incluyendo la importancia que se debía dar a las Escuelas Normales y cómo organizarlas. A los nueve temas que se habían planeado de antemano, se añadió uno sobre la educación de la mujer, posiblemente debido a la presencia en el evento de un buen número de maestras (Congreso Pedagógico Centroamericano, 1894).

Un año después del Congreso, las autoridades salvadoreñas reorganizaron el Colegio Nacional de Señoritas y le dieron de nuevo el nombre de Colegio Normal de Maestras con un currículo más acorde con los avances de la 
pedagogía (“Editorial”, p. 730). ${ }^{12} \mathrm{La}$ necesidad de profesionalización de las maestras saltaba a la vista (Diario Oficial, pp. 1175-1176). A las puertas del siglo $X X$, hubo avances en el número de maestras y en su espíritu profesional como mujeres trabajadoras. Las estadísticas de 1894 para el departamento de Cuscatlán muestran 27 plazas en las escuelas para hombres y 24 para mujeres. Había en el departamento siete directores, siete subdirectores, cinco directoras y siete subdirectoras. La situación en el departamento de La Paz era muy similar (Barberena, 1912, p. 128).

Ya en 1912 los hombres estaban en minoría en el magisterio. Ese año había 531 mujeres en la docencia en comparación con 444 hombres. (Barberena 1912, p. 128). Además, la tendencia era creciente tanto por el aumento en la proporción de mujeres maestras como por el mayor número de escuelas. Para el fin de la primera década del siglo la Escuela Normal de Maestras matriculaba a casi 300 futuras docentes que al compartir experiencias y aspiraciones comenzaban a formar una comunidad profesional (Fonseca, Primer Anuario Estadístico de San Salvador 1910, p. $83^{13}$. El creciente sentido de una comunidad profesional específica de maestras se manifestaba en iniciativas como la revista La Escuela de El Salvador, que empezaron a publicar en 1895 un grupo de maestras bajo el liderazgo de Adela Orantes, directora de la Escuela Superior de Niñas (Flores Montalvo, 2013).

Durante estos años muchas jóvenes aprovecharon un incremento gradual de opciones de capacitación para el trabajo en otras áreas. En 1904, el Estado tomó la iniciativa de crear un nuevo centro educativo en San Salvador para preparar a la mujer para el mercado laboral: el Colegio Técnico Práctico de Señoritas. La institución fue un éxito inmediato. ${ }^{14}$ En uno de sus informes Adela Orantes, la directora del Colegio, explicaba que su objetivo era buscar "nuevos derroteros para la mujer salvadoreña" $y$ "formar mujeres aptas para la lucha por la existencia". Para cumplir con su misión el colegio impartía clases de tipografía, telegrafía, telefonía, fotografía, grabado y encuadernación; además de temas más tradicionalmente "femeninos" como corte y confección, flores de lienzo y arte culinario. (El Salvador. Ramo de Instrucción Pública 1917, p. 76). Las aulas de la institución desbordaban con estudiantes que llegaban de los diferentes departamentos de la República. En 1913, el personal docente tuvo que hacer una solicitud formal para que les dieran un local más amplio (El Salvador. Ramo de Instrucción Pública 1914, p. 24). ${ }^{15}$ Más de 200 muchachas asistían en enero de 1915. 
La popularidad del TécnicoPráctico se mantuvo durante el periodo que cubre este artículo. Para 1920 tenía 300 alumnas. Algunas de ellas eran centroamericanas que se habían desplazado desde sus países, atraídas por su fama (Diario Oficial, 20 de marzo de 1920, p. 482). La sección de tipografía del Colegio tenía su propia revista llamada $L a$ Mujer Salvadoreña (López Vallecillos 1964, p. 234).
Ante la dificultad de obtener estadísticas precisas sobre la composición de género del personal en los diferentes sitios de trabajo, las fotografías pueden arrojar alguna luz. En la Figura 1 se puede observar la presencia significativa de mujeres en la Imprenta Nacional. La foto, que probablemente se tomó en 1912, sugiere que las graduadas de los nuevos centros educativos encontraban colocación en el campo que escogían.

\section{FIGURA 1}

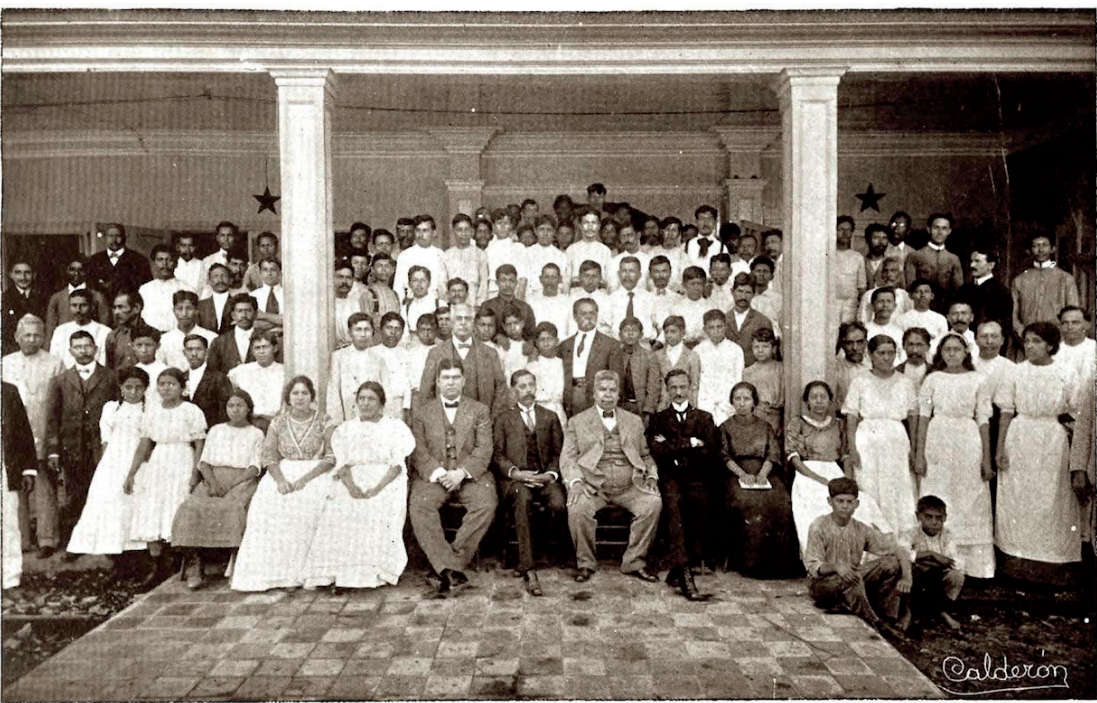

El SR, PREsidente DR. ARAujo En La Imprenta NACIONAL.

Entre las dos columnas, de izquierda a derecha: Dr. Castro Ramirez, Ministro de Relaciones Exteriores, Justicia y Beneficencia Dr. Araujo, Presidente de la República; Dr. Carranza, Ministro de Gobernación, Fomento, Instrucción Publica y Agricultura; y Dr. En segundo término detrás del Dr. Carranza, el Director de la lmprenta Nacional don Próspero Calderón. a la derecha de ésdon Francisco R. González (Fósforo), primer corrector de pruebas. A la izquierda del fotograbado, los señores Lanza y Monches, Guarda-Almacén y Cajero respectivamente. Completan el cuadro, empleados, cajistas, prensistas y encuadernadores.

Como la idea de una formación "técnico-práctica" para capacitar a mujeres para el mundo laboral tuvo buena acogida, pronto surgieron imitadores. En 1917 se fundó en Santa Ana un anexo al Asilo Santa 
Narcisa de las hermanas betlemitas con una escuela técnico-práctica para jovencitas ("Vida Salvadoreña", p. 7141). Ese mismo año una escuela privada de San Salvador que se promovía como "Escuela de Comercio" abrió otra entidad que ofrecía "complementación con carácter profesional para mujeres" y la Escuela de Complementación anexa a la Escuela Superior de Niñas "Froebel" daba clases de contabilidad, dibujo topográfico y mecanografía. ${ }^{16}$

La profesión de enfermera también era una opción para las mujeres. A principios de siglo también comienzan a darse intentos para elevar su nivel educativo. En 1917, el gobierno contrató en París a la profesora obstétrica, señorita A. Auramboux para dirigir una escuela de parteras y enfermeras (El Salvador. Ramo de Instrucción Pública, 1918, p. 16) La escuela se mantuvo pequeña en los primeros años (En 1919 tenía 20 alumnas), pero abrió el camino para la profesionalización de la enfermería (Diario Oficial, "Memoria de Instrucción Pública”, p. 485.)

Las mujeres también aprovecharon las oportunidades de formación profesional en la Escuela de Artes Gráficas que se fundó en 1913. Aunque no contamos con estadísticas precisas, podemos ver en una foto de un grupo de alumnos tomada alrededor de 1921 (Figura 2) que aproximadamente una tercera parte eran mujeres. Esta escuela, famosa por su formación de artistas, también impartía clases de mecanografía y estenografía, materias útiles para entrar al mundo laboral en el comercio y oficinas privadas y gubernamentales. ("Nuestro Centro de Enseñanza”, p. 1645). 

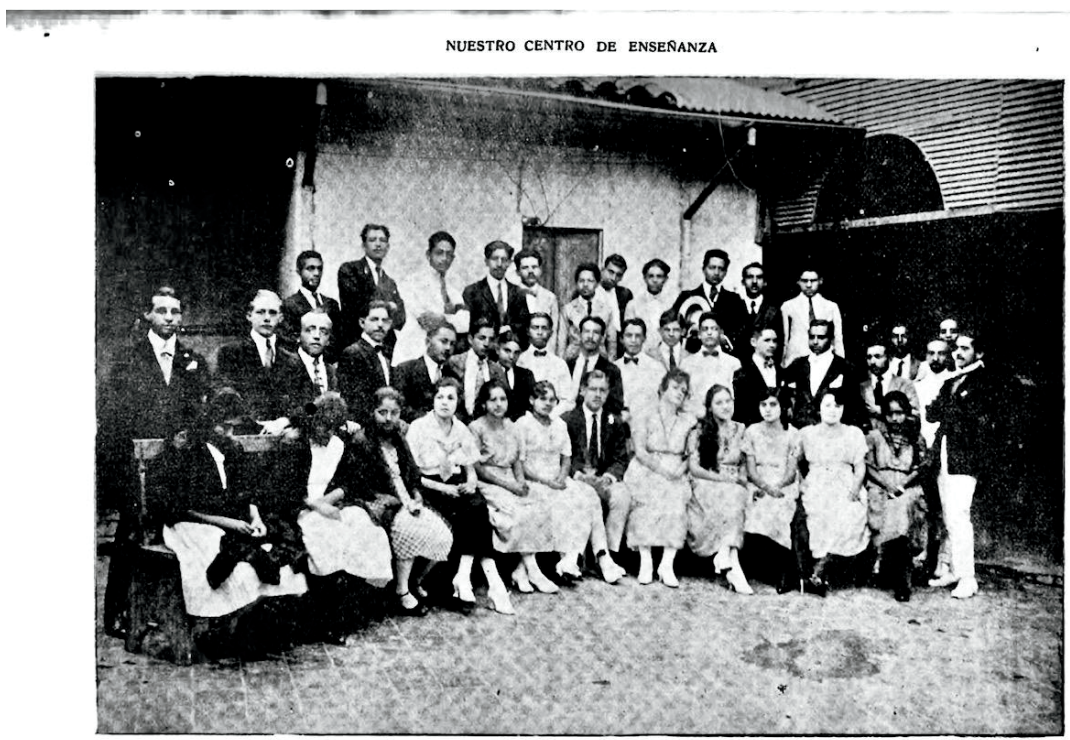

Grupo de alumnos de la Escucla de Artes Gráficas fundada por el Dr. Alfonso Quiñonez M. + Pedro A. Mena, profesor de la Sección de Mecanografia
Estenografia

La creciente incorporación de mujeres a nuevas ocupaciones se dio en un periodo en el que había un considerable ímpetu asociativo en las ciudades y pueblos del país. El presidente Escalón se refería en un discurso al "creciente espíritu de asociación que ha venido despertándose entre las clases obreras" ("Mensaje del señor presidente de la República del Salvador", p. 282.) Este empuje que Escalónobservaba en 1904, se aceleró en las dos décadas siguientes. Entre 1900 y 1920 se organizaron gran número de asociaciones de ayuda mutua de artesanos y obreros. Estas asociaciones eran prácticamente inexistentes antes del siglo XX, pero al terminar la segunda década del siglo había al menos 78 repartidas por todo el país. ${ }^{17}$ El gremio de tipógrafos, donde había una presencia femenina significativa, era uno de los más activos políticamente de la época.

Abundan los ejemplos de mujeres que se habían incorporado al mundo del trabajo y querían participar en esta nueva forma de sociabilidad. Las maestras se encontraron entre las primeras en incorporarse a asociaciones profesionales. En 
1904 la membresía de la Sociedad Pedagógica de El Salvador incluía a varias de ellas incluyendo a Adela Orantes. (Flores Montalvo, 2013) Por su lado, varias empleadas de establecimientos de San Salvador tocaron a la puerta de la Sociedad de Empleados de Comercio. La agrupación las eximió de los cinco pesos de inscripción ("Gremios y corporaciones", p. 3). Cuando se organizó la Sociedad Central de Maestros en 1914, maestras como Josefina Mendoza y Teresa Masferrer quisieron estar entre sus primeros miembros. (El Salvador. Ramo de Instrucción Pública 1915, p. 91)

El siguiente paso era organizar asociaciones exclusivamente para ellas. Éstas podían ser de señoras de estratos sociales altos, como el "Club Femenino Reformista" fundado en la ciudad de San Miguel en 1918 (El Nuevo Tiempo, p. 9283) También podían ser obreras organizadas en una sociedad de ayuda mutua, como la que presidía María Martínez en 1917 ("Fundación de una sociedad de ahorros y protección mutua de jóvenes obreras", Diario del Salvador, p. 2) Las costureras se reunieron en San Salvador en 1920 para establecer una organización con el objetivo de "el mejoramiento, moral intelectual y económico de la clase trabajadora en general y en particular el gremio de costureras". El titular del periódico que anunciaba al nuevo grupo lo calificaba de "movimiento feminista salvadoreño" ("Movimiento feminista salvadoreño. Se constituye la sociedad de mujeres trabajadoras" $p$. 1). En 1921, el Diario Oficial publicó la aprobación de los estatutos de la Sociedad Femenil "El Porvenir de la Mujer", que organizó un grupo en Santa Ana. Los estatutos eran muy similares a los de las asociaciones de ayuda mutua de obreros que promovían "el principio del ahorro y el auxilio mutuo". La diferencia es que el criterio para pertenecer a esta sociedad no era ser parte de un gremio específico, sino ser mujer con una "profesión, arte, oficio, industria, renta" o manera lícita de ganarse la vida ("Estatutos de la Sociedad Femenil 'El Porvenir de la Mujer", p. 265.)

Estas mujeres preparadas, que trabajaban fuera del hogar e integraban organizaciones, buscaban incidir en el debate político, aportando sus puntos de vista. Un ejemplo de esto es Teresa Masferrer. La brillantez de su hermano Alberto ha opacado injustamente sus contribuciones pioneras como autora y activista. Ella era una intelectual por derecho propio y sus contemporáneos la reconocían como tal. Cuando se afilió a la Sociedad Central de Maestros al fundarse la asociación en 1914, esta maestra ya tenía una trayectoria que se destacaba por su iniciativa, actitud progresista y sensibilidad social. Su libro Nociones de higiene, publicado en 1911, fue un importante esfuerzo de síntesis de conocimientos 
higiénicos que ella adaptó con gran habilidad al contexto salvadoreño. La obra fue muy bien recibida al grado que se utilizó como texto escolar por más de una década (Masferrer, 1911). Las sociedades de artesanos la invitaban a sus reuniones anuales a hablar sobre temas variados, desde al alcoholismo (tema que discute en su libro), hasta el unionismo. En 1912 se había hecho cargo de la dirección de una escuela nocturna para obreras. El año siguiente fue la única mujer en el grupo de intelectuales que fundó el Ateneo de El Salvador. Más adelante participó en el proyecto de la Universidad Popular, una iniciativa de la Sociedad de Obreros de El Salvador Confederada, con el apoyo de intelectuales como Salvador Merlos para ilustrar a artesanos y obreros.

Encontramos esta voluntad de incidencia en el espacio público en mujeres de todos los grupos sociales. Cuando el presidente Araujo visitó Zacatecoluca en enero de 1913, las señoras del mercado le dieron la bienvenida presentándoseasímismas como obreras y actores políticos por derecho propio. Construyeron un hermoso arco triunfal de bienvenida y su representante pronunció un elaborado discurso para darle la bienvenida "ofreceros nuestro hogar, qué como de obreras, es humilde, pero en cuyo seno se rinde culto a lo noble, a lo bueno, a lo grande, a lo justo."A lo largo del discurso continuó refiriéndose a su grupo como obreras
("La simpática manifestación de las señoras del mercado. Entusiasta discurso de una señorita", p. 1.)

Las vendedoras de los mercados se hacían presente en los momentos más relevantes de la vida cívica. En febrero de 1916, cuando la Junta Patriótica de Obreros organizaba una manifestación en homenaje a la memoria del doctor Araujo en el tercer aniversario de su asesinato, el comité de señoras del mercado decidió, de forma paralela, extender su propia invitación al evento ("La manifestación obrera en homenaje al doctor Araujo", p. 1). Así dejaban en claro que eran actores políticos autónomos.

Mujeres que se dedicaban a la tipografía, posiblemente algunas de ellas graduadas del Colegio TécnicoPráctico, se afiliaban a la Sociedad de Tipógrafos. Sus intervenciones en los debates no siempre eran bienvenidas en una sociedad patriarcal. En 1914 el comportamiento de la señorita Gutiérrez Muñoz irritó tanto a sus colegas tipógrafos que tres de ellos solicitaron su expulsión por disociadora ("No ha sido expulsada de la sociedad de tipógrafos la señorita Gutiérrez Muñoz", p. 2).

A la convención de asociaciones obreras en enero de 1921 asistieron representantes de la Sociedad de costureras "El Despertar". Ellas no estaban en la convención como meras oyentes, una de sus miembros, 
la señorita Ana María Bonilla, la Universidad. Afortunadamente era la tesorera del evento y fue para la nueva institución, "el Dr. delegada para asistir a una reunión Merlos, con la energía y oportunidad con el presidente de la República. que se requiere en tales casos, hizo ("Convención de sociedades Obreras", p. 2). Un incidente en la Universidad Popular alrededor de 1924 da una idea de la creciente presencia de mujeres en actividades obreras. Un grupo al interior de Sociedad de Obreros Federada provocó una disrupción seria en las clases. Algunos temían que el incidente era parte de una conspiración contra la iniciativa de reponer las vacantes con decididas señoritas presentes y amantes de la instrucción, haciendo comprender, en su alocución comedida, que si los hombres niegan su contingente en la obra de regeneración obrera, las mujeres pueden también sustituirlos con resultado feliz" (Federación de Obreros de El Salvador, 1924, p. 43).

\section{Unionismo}

Al acercarse la década de 1920 , se encuentran cada vez más ejemplos de mujeres que se abrían camino, saltando barreras y haciendo oír su voz en los principales temas de interés nacional. Sus intereses iban más allá de preocupaciones gremiales. La principal causa que inspiraba el accionar político de mujeres organizadas era el antiimperialismo, que se fusionaba en el discurso político de la época con el unionismo.

El entusiasmo de las mujeres con la causa unionista no se explica por sí solo. El contexto lo daban los enormes cambios geopolíticos en la zona de Centroamérica y el Caribe.
Los centroamericanos nunca habían abandonado la idea de regresar a la federación. Los primeros intentos de reunificar el istmo fueron vehículos para ambiciones caudillistas. Primero del guatemalteco Justo Rufino Barrios (1885) y luego del nicaragüense José Santos Zelaya (1895-1898) trataron de unir a los países del istmo. Pero al mismo tiempo que fracasaba la República Mayor de Centroamérica que promovió Zelaya, el equilibrio de poder hemisférico estaba cambiando radicalmente. Salvador Mendieta, el principal pensador unionista de la época, reconoció el significado del momento: se acercaba el "peligro yanqui". En 1903 escribió que "tras la conquista de Cuba y Puerto Rico por los Estados Unidos vendría la 
conquista de Santo Domingo y tras la de este, el avance yanqui sobre el codiciado centro de América" (Mendieta, 1903, p. 139)

En efecto, después de la Guerra Hispano-estadounidense (1898), Cuba y Puerto Rico quedaron bajo el control político de Washington. En menos de una década los intereses del imperio separaron a Panamá de Colombia y comenzó la construcción del canal. Ésta era la obra de ingeniería más importante del mundo y colocaba al istmo centroamericano en el vértice de enormes intereses geopolíticos y comerciales. Más cerca de El Salvador, en Nicaragua, el gobierno era poco más que un títere del gran poder del norte. La población de $\mathrm{El}$ Salvador se alarmó sobremanera, particularmente después de que los marines desembarcaron en costas nicaragüenses en 1912. Todo indicaba que la soberanía salvadoreña estaba en peligro. La vulnerabilidad ante el poderío estadounidense provocó sentimientos antiimperialistas y renovó el sueño de la unión de Centroamérica. El sentimiento general era que los cinco países unidos tendrían más posibilidades de resistir con éxito las ambiciones hegemónicas de Estados Unidos.

La idea de revivir la federación centroamericana se convirtió en tema urgente. De esta forma el movimiento unionista de principios del siglo XX iba de la mano de la causa antiimperialista. A partir de 1912, después de la invasión estadounidense a Nicaragua, la agitación popular alrededor del tema antiimperialista fue considerable. Las asociaciones de artesanos, obreros, estudiantes y profesionales se movilizaron para hacerle frente a la amenaza imperial. Estas eran las mismas asociaciones a las que se estaban afiliando las mujeres urbanas. Las primeras causas que ellas abrazaron fueron las del antiimperialismo y el unionismo.

Una sucesión de acontecimientos después de la invasión de Nicaragua inflamó periódicamente el sentimiento antiimperialista. Primero, la negociación del Tratado Chamorro-Bryan con onerosas concesiones nicaragüenses a Estados Unidos. El acuerdo afectaba a El Salvador con la posibilidad de una base en el Golfo de Fonseca. Luego la firma del tratado (1914), su ratificación (1917) y, finalmente, el proceso legal en contra de este que prosiguió el gobierno salvadoreño fueron causa de mucha agitación popular.

Después de la ratificación del tratado en 1917, el presidente de Honduras, Francisco Bertrand, propuso la unión de Centroamérica, proyecto que, aunque tuvo corta vida, dio lugar a mucho trabajo organizativo. Al llegar 1920, la proximidad de la importante efeméride de 1921, el primer 
centenario de la independencia de Centroamérica, dio impulso a la idea de revivir la Federación. La coyuntura era favorable, porque el gobierno guatemalteco, después de la caída del dictador Estrada Cabrera en 1920, tenía una fuerte agenda unionista. Ese año, los presidentes de Centroamérica acordaron enviar representantes a una reunión en Costa Rica para escribir un pacto de Unión.

El Pacto de Unión que se firmó el 19 de enero de 1921 planteaba escribir una Constitución Federal que debía de estar lista para el centenario. Las dificultades que rodeaban al pacto eran enormes. Los nicaragüenses, bajo presión estadounidense, se negaron a firmar el documento. los costarricenses firmaron, pero luego la legislatura de ese país no quiso ratificarlo. Solamente quedaron Honduras, Guatemala y El Salvador. A pesar de la oposición interna en cada país, los tres países continuaron su compromiso con el pacto.

Las salvadoreñas pusieron de manifiesto su voluntad de ser oídas en cada uno de los hitos de esta historia, desde la percepción de la amenaza imperialista y la renovación del unionismo hasta el Pacto de Unión y la Constitución Federal. El trabajo de Patricia Fumero muestra que las centroamericanas utilizaron la esfera pública en el contexto de las celebraciones del centenario "para abordar sus inquietudes y presentar sus identidades públicamente" (Fumero-Vargas 2005, p. 32) Se puede añadir que cuando llegaron las celebraciones del centenario ya estaban activas en las causas del antiimperialismo y el unionismo.

Uno de los primeros ejemplos de salvadoreñas participando en la causa unionista con una agenda de carácter feminista se encuentra en 1911, durante las celebraciones del centenario del Primer Grito de Independencia. En esos días las maestras del Colegio de Señoritas de Ahuachapán decidieron formar un club unionista femenino. Enviaron una carta al Comité Unionista de Ahuachapán mencionando la corriente feminista en países de Europa y el norte de América y lamentando que en El Salvador ninguna participación se ha dado "al sexo femenino en la resolución de los problemas políticos y sociales que entrañan el porvenir cada vez más amplios de los pueblos cultos y civilizados". Sin embargo, ellas no estaban dispuestas a quedarse al margen y estaban decididas a formar un grupo unionista solamente de mujeres ("Campaña unionista. Una nota del comité de Ahuachapán", p. 1).

El deseo de emular el movimiento feminista, particularmente del mundo anglosajón, se reflejaba en publicaciones ocasionales en los periódicos. En 1911 un artículo que apareció en el periódico Vox Populi intitulado "Habla una señorita" 
abogaba por la participación de la mujer en la solución de los grandes problemas sociales y políticos de la región diciendo que "Puede la mujer centroamericana terciar de algún modo en la persecución del gran ideal que se ventila en la actualidad, cómo es el de la Unión Centroamericana." (“Habla una señorita”, p. 1.).

La amenaza imperial que daba tanto impulso al movimiento unionista se hizo sentir con particular fuerza cuando fuerzas estadounidenses invadieron Nicaragua en 1912. Los rebeldes nicaragüenses que se enfrentaban a los marines invasores contaron con el apoyo de salvadoreños antiimperialistas que viajaron al país vecino a incorporarse a la lucha. Entre estos últimos se encontraba Lucila Matamoros. Ella se destacó tanto que le dieron un rango de oficial en el ejército nicaragüense. Desafortunadamente, la capturó el enemigo y terminó ahorcada ("Las heroínas de la revolución libertadora de Nicaragua", p. 2). Prudencia Ayala la menciona en sus memorias como modelo de conducta.

Las mujeres buscaban diferentes mecanismos para expresar su antiimperialismo. Uno de ellos era a través de las carrozas que desfilaban en las fiestas patronales. Siguiendo una tradición muy antigua en $\mathrm{El}$ Salvador, durante las fiestas de los patronos de ciudades o pueblos se organizaban desfiles de carrozas que llevaban alegorías religiosas o con contenido político. En 1912, por ejemplo, el desembarco de los marines en el puerto de Corinto coincidió con las fiestas agostinas de San Salvador. En esa ocasión las señoras del barrio Cisneros organizaron una carroza de desafío al imperialismo en la que cinco muchachas representando a los países de Centroamérica se rodeaban con un defensor armado, un niño con un cañón ("Días agostinos", p. 1.). Este tipo de performance de resistencia enraizada en tradiciones locales se repetía en todo el país, invariablemente con mujeres como protagonistas.

Al terminar el conflicto de Nicaragua, la llegada de refugiados nicaragüenses, en su mayoría miembros de las fuerzas rebeldes derrotadas, dieron una oportunidad más para que las salvadoreñas demostraran su antiimperialismo. Las obreras del mercado se apresuraron a auxiliar a los derrotados organizando colectas y hasta donando puros de tabaco. ("Las obreras del mercado y los emigrados de Nicaragua”, p. 4.)

Una nueva fiebre antiimperialista y unionista siguió a la iniciativa de unión del presidente Bertrand en 1917. El Comité Central Unionista hondureño envió a El Salvador a Rafael Alduvín como delegado para promover la idea ("Nuestros delegados", p. 2). Alduvín encontró excelente acogida entre 
las salvadoreñas. En el pueblo de Guazapa, departamento de San Salvador, un grupo organizó el "Club Unionista de Señoritas Bellos Horizontes" para apoyar la iniciativa hondureña ("El patriotismo de la mujer salvadoreña”, p. 5). En occidente la asociación "Mengalas Unionistas en Ahuachapán” tenía el mismo propósito. ${ }^{18}$ Más prominencia social tenían Delfina Lagos y Cristina Padilla, ambas organizadoras del "Comité Unionista de Señoras y Señoritas de Ahuachapán" (Comité Unionista de Señoras y Señoritas de Ahuachapán”, p. 2). Las distinguidas ahuachapanecas invitaron a los delegados hondureños para entregarles una medalla de oro que habían concedido al mandatario hondureño. En el discurso de entrega, Delfina Lagos, presidenta del grupo, realizó malabarismos retóricos con la idea patriarcal de la mujer como compañera del hombre: "Estamos dispuestas a ayudaros en todo," dijo doña Delfina, "pues creemos que cuando la mujer se propone algo benéfico y grandioso, no hay nada que resista a su empuje. Los hombres, como dignos compañeros de ella, habrán de disputarse el honor de secundarla y sostenerla." Las unionistas de Ahuachapán demostraron un compromiso admirable con la causa y viajaban a los pueblos a fundar comités locales. A ellas se debió la organización de las mujeres de San Pedro Puxtla, una pequeña población al este de la ciudad ("Actitud patriótica del comité de señoras y señoritas de Ahuachapán”, p. 1). ${ }^{19}$

La iniciativa de Bertrand fue otro intento que fracasó, pero los unionistas no se daban por vencidos. A finales de 1918, el Partido Unionista de Salvador Mendieta celebró una convención en el puerto de La Unión. Al evento asistieron los unionistas salvadoreños más distinguidos, incluyendo a Alberto Masferrer y Salvador Merlos, pero no había mujeres entre los representantes oficiales. Incidentalmente, la convocatoria enfrentó problemas debido a la pandemia de influenza que había cobrado muchas víctimas. La delegación guatemalteca no confirmó su asistencia hasta última hora debido a la pandemia ("La convención en el Puerto de La Unión”, p. 9266).

Muchas mujeres, que ya para entonces se habían perfilado como uno de los puntales del movimiento unionista, se encontraban entre el público que se allegaba a escuchar las deliberaciones de la Convención. No salieron decepcionadas. El corresponsal del periódico hondureño El Nuevo Tiempo informó: "La Convención reconoció los derechos políticos, dentro del Partido Unionista, de la mujer centroamericana" ("La convención unionista de El Salvador", p. 9290). Además, el delegado salvadoreño, Alberto Masferrer, habló de forma elocuente de la necesidad de apoyar 
el magisterio, tema que era de indudable interés para las mujeres ("La convención unionista de El Salvador", p. 9290).

Los delegados a la convención de La Unión pensaban que el fin de la Primera Guerra Mundial podía presentar una coyuntura internacional favorable al movimiento unionista, pero no fue así. El proyecto tenía muchos obstáculos, empezando por la oposición regional en países como Guatemala, donde al presidente Estrada Cabrera solamente le interesaba una unión de Centroamérica bajo su control personal. Esta situación cambió cuando un poderoso movimiento que incluía a estudiantes, profesionales y mujeres derrocó al dictador y llevó al poder a Carlos Herrera. El ideal del unionismo fue uno de los principales aglutinadores del movimiento contra la dictadura y las mujeres, grandes campeonas del ideal, desempeñaron un papel prominente en el proceso.

Según relata Salvador Merlos, "las mujeres marchaban a la par de los hombres en aquellas jornadas memorables que abrieron nuevos horizontes al pueblo guatemalteco; y después, cuando la tiranía descargó sobre el pueblo la furia de sus metrallas, la mujer estuvo presente y soportó con estoicismo las inclemencias de aquella lucha desigual" (Merlos 1921, p. 86).
Este espíritu se transmitió a las salvadoreñas que, como hemos visto, ya eran favorables a los ideales de Morazán. "Y ahora que el unionismo pasea sus banderas victoriosas en la sección de Guatemala," dice Merlos, "la mujer salvadoreña ha recogido el eco de aquellos himnos libertarios $y$, pletórica de entusiasmo, ha entrado en la campaña unionista dándole todo el fuego de su corazón [...] En Santa Ana, en Chalchuapa, en Santa Tecla y en numerosas poblaciones del Estado, los centros femeninos de propaganda unionista han surgido como manantiales de esperanza" (Merlos 1921, p. 88)

Entre las salvadoreñas que recogieron "el eco de aquellos himnos libertarios”, la más prominente fue Prudencia Ayala. Ella se involucró tanto en el movimiento guatemalteco que terminó encarcelada en 1919, episodio que relata en un folleto intitulado Escible. Aventuras de un viaje a Guatemala, que menciona en sus memorias (Ayala, 1925, p. 106)..$^{20}$ Ella escribe sobre el triunfo de la lucha contra Estrada Cabrera como inspiración para continuar con la causa no solamente del unionismo sino también de una verdadera transformación política: "qué hermoso el porvenir que veo despuntar en cuanto se lleve a cabo la unión de Centro América en una sola República. La vida será progresar y no tiranizar, desde ese momento en que la justicia nacional va alcanzando libertad $y$ 
fraternidad en la buena voluntad de los sentimientos del hombre" (Ayala, 1925, p.108; Ticas 2001, p. 42).

En el discurso de Ayala las causas del antiimperialismo, el unionismo y los derechos políticos de las mujeres estaban vinculados. En sus obras ella reproduce los artículos que publicaba en los periódicos de Santa Ana donde elaboraba estas ideas. Vale la pena citar con cierta extensión un artículo que publicó en el Diario de Occidente a mediados de 1918:

\section{“Qué dirá el señor presidente Wilson de la mujer centroame-}

ricana? ¿Qué dirá de los comentarios qué hace de sus palabras ante la situación europea y de la violación de los derechos de nuestra querida Centroamérica? ¿Comprenderá que el ciudadano centroamericano, cuenta con una mujer, no solamente para el ejercicio del hogar, sino también para ayudarle a preocuparse en el momento histórico presente de lo interesante de la patria? ¿Comprenderá que en el corazón de la mujer centroamericana, está prendido en ese fuego del más leal y acendrado patriotismo, como lo prueban los hechos, la vida de la heroica y valiente Lucila Matamoros, que dio pruebas de su amor y lealtad a la patria y a la libertad? Comprenderá que así como hay hombres que venden su honor para cubrir de vergüenza el rostro, hay también hombres de carácter concienzudo que saben estimar y defender las leyes y sacrificarse en derecho en aras de la justicia con patriotismo espartano". (Ayala, 1925, p. 134). ${ }^{21}$

Por lo menos desde sus tiempos en Guatemala, y posiblemente desde mucho antes. Ayala hablaba del sufragio femenino, tema que en 1920 estaba particularmente visible con la aprobación de la enmienda a la constitución estadounidense que otorgaba el derecho al voto a las mujeres de ese país. Refiriéndose a sus actividades políticas en Guatemala uno de sus escritos autobiográficos dice: "No he tenido otro interés, que el bien todos, puesto que bien sabéis que no goza del sufragio que en justicia merece la mujer, para tomar parte en los comicios electorales con toda garantía a su vida e interés, y ocupar puestos que sus actitudes pueden desempeñar" (Ayala, 1925, p. 112). Sonia Ticas resume la postura política de Prudencia Ayala cuando dice que "para ella, la ciudadanía no consistía puramente del derecho al sufragio, sino requería de una fuerte militancia política para garantizar las prácticas y principios democráticos" (Ticas, 2009).

La subida al poder de un gobierno abiertamente unionista 
en Guatemala y la cercanía de 1921 centenario de la independencia, dio un nuevo impulso al movimiento tanto en círculos oficiales cómo entre los grupos antiimperialistas y unionistas que llevaban años luchando por la causa.

En junio de 1920, después de meses de presión popular, la cancillería salvadoreña puso en marcha el proceso con la convocatoria de una reunión de plenipotenciarios en Costa Rica para tratar el tema de la unión de Centroamérica.. ${ }^{22}$ El tema pasó al centro del debate nacional. La Prensa, que apoyaba con entusiasmo la causa unionista, hizo un llamamiento a un congreso de representantes de todos los clubs unionistas de Centroamérica ("Res non verba: esto exige el unionismo del momento", p. 1).

Del 5 al 7 de noviembre hubo una convención del partido unionista en San Salvador, en el Teatro Nacional. La segunda sesión la presidió la señorita Carlota Herrera Otondo, que fungía cómo cuarta vocal de la directiva. En los meses anteriores se habían organizado numerosos grupos unionistas y uno de los propósitos de la convención era darle coherencia al movimiento político. Varios de esos grupos eran de mujeres lo que explica la presencia de dos de ellas en la directiva de la convención, la tercera vocal, Dolores de Turcios y la cuarta vocal, la señorita Herrera Otondo ("Detalles de la convención del partido unionista celebrada en San Salvador el 5 de noviembre", pp. $1,5)$.

La reunión de plenipotenciarios comenzó en Costa Rica en diciembre de 1920. Los grupos de la sociedad civil, conocedores de las dificultades del proyecto de unión, decidieron que era necesario dar a conocer al gobierno el sentimiento popular. Es así como poco antes de que saliera la delegación salvadoreña con destino a San José, un grupo de 83 señoras de Ahuachapán, entre las que se encontraban los apellidos más distinguidos de la ciudad como Magaña y Morán, escribieron a los diputados de la Asamblea Nacional urgiéndoles para que apoyaran la unión de Centroamérica. Entre ellas estaba Estefanía Juhl, una de las damas que había dado la bienvenida a los hondureños en 1917 ("La mujer salvadoreña en la campaña unionista”, p. 2).

Salvador Merlos explicaba de la siguiente manera el entusiasmo asociativo de las mujeres: "Las agrupaciones políticas que se forman cada 4 años, generalmente para disimular falsas electorales, no han merecido la participación femenina, qué busca siempre, en un campo ideal, las más altas manifestaciones del espíritu. [...] Pero hoy, estando de por medio el ideal morazánico, la mujer ha encontrado un florido sendero por dónde echar a correr su fantasía, un campo lleno de 
esperanzas, una bandera limpia y redentora" (Merlos, 1921, pp. 82-83).

Merlos añade que el activismo político de mujeres era un fenómeno centroamericano que incluía el club unionista femenino de Tegucigalpa, la participación de las mujeres en Nicaragua para conservar la autonomía, el papel de las maestras del colegio normal de Costa Rica en la revolución contra la dictadura de los Tinoco, y el papel de las mujeres en Guatemala para derrotar a Estrada Cabrera (Merlos, 1921, p. 85).

Los plenipotenciarios en Costa Rica no llegaron a un acuerdo sobre la unión antes de que terminara 1920, como era su meta. El principal obstáculo tenía que ver con los compromisos del gobierno de Nicaragua con Estados Unidos. Mientras estaban reunidos los diplomáticos en la cancillería costarricense, los grupos unionistas continuaron con su propaganda de apoyo a la renovación de un pacto federal.

Prudencia Ayala ejercía
un liderazgo notorio en este movimiento. Una de sus actividades era dar conferencias públicas en los teatros. Sus presentaciones, como la que hizo el 3 de enero en el Teatro Principal, recibían profusos aplausos del auditorio. Esta mujer de origen muy humilde, con poca educación formal, había destacado tanto por su oposición al imperialismo y apoyo al unionismo, que la invitaban a hablar en un teatro donde se presentaban intelectuales como Alberto Masferrer. ${ }^{23}$

Es útil ampliar el contexto de estas conferencias en el Teatro Principal porque este es un fenómeno que ahora nos resulta ajeno. Un teatro como el Principal, o el Colón, donde también hablaba Prudencia Ayala, se utilizaba de formas diversas. Era el escenario para compañías extranjeras, principalmente mexicanas que presentaban obras de teatro. En él se daban conciertos de música popular y clásica y se presentaban películas de cine mudo. Hace 100 años el entretenimiento que, a principios del siglo $\mathrm{XXI}$, encontramos frente al televisor, requería la asistencia a un teatro. Siguiendo esta analogía con la pantalla de televisión, las conferencias públicas equivalían a los programas en los que diferentes expertos discuten los problemas del momento para informar a los televidentes. En las conferencias de los teatros se presentaban intelectuales como Alberto Masferrer, Raúl Contreras, Prudencia Ayala y Salvador Merlos, que hablaban sobre los temas de interés del momento que a principios de la década de los 20 incluían al unionismo. Este formato tenía la ventaja de que no requería saber leer y por lo tanto llegaba a buena parte de la población urbana donde todavía existía un buen porcentaje de analfabetismo. ${ }^{24}$ 
Entre el público se encontraba gente de todas clases sociales.

Las conferencias en los teatros no eran costumbre exclusiva de la capital. Una noticia del pueblo de Quezaltepeque describe parte de la audiencia en una de ellas. Entre los asistentes se encontraban "Sufridas y abnegadas mengalas qué, tras las rudas faenas de la máquina 'Singer', van gozosas y entusiastas a dar vida al salón de conferencias, con su voz que es sinceridad y con su sentir que es el patriotismo" ("Cómo celebró Quezaltepeque la firma de la Unión", p. 3).

Ante estos públicos, Prudencia Ayala explicaba sus ideales que combinaban el unionismo con la importancia de la participación política de las mujeres. Sus palabras deben de haber resonado con las "mengalas", como se les decía a las trabajadoras urbanas de las clases más pobres..$^{25}$ En una de sus conferencias decía: "viva el triunfo del patriotismo femenino viva el progreso viva la gloriosa unión de nuestra amada patria Centroamérica vivan los gobernantes que cumplen con su deber de realizar la causa viva contestó el auditorio". Así era el liderazgo que ejercía Prudencia Ayala el año del centenario de la independencia.

Los plenipotenciarios en Costa Rica firmaron el Pacto de Unión el 19 de enero. El siguiente paso era la ratificación de parte de las legislaturas de cada país. $\mathrm{Ni}$ en El Salvador ni en los demás países había certeza sobre dicha ratificación, razón por la cual el liderazgo del movimiento unionista decidió mantener la presión con propaganda, celebraciones y manifestaciones que a la vez que celebraban la firma del documento era una demostración de fuerza.

La población de Sonsonate celebró con gran entusiasmo. Al enterarse de la noticia, las sonsonatecas organizaron una carroza que transitó las calles de la ciudad llevando a la señorita Marina Gallont representando a Centroamérica. Más adelante, el Comité Unionista de Señoras organizó un baile muy suntuoso ("Manifestaciones populares por la Unión", p. 5).

Quezaltepeque celebró con una manifestación en la que participó de manera prominente el Comité Unionista Femenino del pueblo qué se hizo cargo de entonar los acordes del himno centroamericano ("Celebrando la firma del Pacto de Unión centroamericana”, p. 4).

El reportaje periodístico sobre una manifestación que hubo en Chalchuapa subrayaba la asistencia de gran número de señoras y señoritas ("Solemne manifestación unionista en Chalchuapa", p. 4). 


\section{Camino al sufragio}

La siguiente iniciativa fue la organización de una gran convención unionista que se celebró a mediados de febrero en Santa Ana, ciudad que se había convertido en el epicentro del movimiento. La población santaneca recibió a los unionistas con entusiasmo. Para celebrar el acontecimiento, las vendedoras adornaron el edificio del mercado con "millares de gallardetes y guirnaldas con los colores federales" (Cardona, 1921, p. 19). El día de la inauguración los delegados recorrieron las calles acompañados por la Banda Marcial. A las ocho de la noche, acompañados por inmensa muchedumbre, los delegados de toda Centroamérica entraron al suntuoso teatro de la ciudad. ${ }^{26} \mathrm{El}$ público abarrotaba los balcones, se habla de más de 4000 espectadores que asistieron a la inauguración donde pudieron escuchar la oratoria de ardientes unionistas incluyendo a la salvadoreña Hercilia Linares (Cardona, 1921, p. 21).

La mayoría de las delegaciones representaban una región geográfica, pero el Comité Femenino Unionista tuvo una delegación separada, que incluía a María Álvarez de Guillén y a Heraclia Bonilla. La primera era miembro de familia terrateniente y la segunda maestra. Por su lado, la Sociedad El Porvenir de la Mujer tenía dos delegadas ("La próxima convención unionista que se celebrará en la ciudad de Santa Ana", p. 4).

Durante una de las sesiones de la convención pidió la palabra la representante de San Miguelito, Prudencia Ayala, para presentar una moción a favor del sufragio femenino. ${ }^{27}$ A pesar de la sorpresa y oposición inicial de muchos, su iniciativa tuvo éxito. Una de las resoluciones del evento unionista fue "que se gestione en la forma debida para que a la mujer se le conceda el derecho de sufragio". (Cardona, 1921, p. 25)

Al salir del evento en Santa Ana, los unionistas tenían muy claro que su "objetivo primordial" era "mantener lo pactado en San José de Costa Rica". (Merlos, 1921, p. 42). Las mujeres habían encontrado en el proyecto unionista una coyuntura favorable para la participación política y la ampliación de sus derechos legales, incluyendo el sufragio.

A juzgar por una noticia de Quezaltepeque, el entusiasmo sobre lo que podría lograr el protagonismo de las mujeres era considerable y ellas formulaban planes ambiciosos. 
Un grupo de mujeres del pueblo propuso la idea de celebrar "una gran convención de mujeres centroamericanas, procurándose el mayor número de Nicaragua, a fin de que allá principie la revolución moral en contra de los enemigos de aquel país hermano digno de mejor suerte. Una vez celebrada la convención, ésta pediría a las mujeres norteamericanas su valiosa influencia a fin de exhibir a los Chamorro en la tierra de Jorge Washington." ("Labor de nuestro corresponsal en Quezaltepeque”, p. 4).

El entusiasmo era grande. La Asamblea Nacional Legislativa aprobó el Pacto de Unión dándole un fuerte impulso al proceso. Miles de personas salieron a las calles de San Salvador para celebrar el decreto legislativo. Las mujeres llevaban en los brazos los colores azul y blanco de la Federación. ("La imponente manifestación unionista de anoche", p. 1).

Las señoras del mercado, que habían mostrado tanto interés en el movimiento unionista, también se ocupaban de los otros problemas políticos del momento. El mismo día en que asistían a la gran manifestación unionista ofrecieron apoyo a los zapateros que se habían declarado en huelga. La acción de los zapateros era totalmente extraordinaria y subrayaba la seriedad de la crisis económica y social por la que pasaba el país. El fin de la Primera Guerra mundial, el comienzo de una recesión en Estados Unidos y desaciertos en la política monetaria crearon una atmósfera de angustia que estalló con los motines del 28 de febrero.

El detonador de los motines fue un decreto que desmonetizaba la moneda fraccionaria de plata. Para efectos prácticos, todos aquellos que tenían ahorros en moneda fraccionaria veían que ésta desaparecía. Las señoras del mercado, insumisas como siempre, estuvieron al frente del movimiento, y el 28 de febrero convocaron a una protesta frente a la Asamblea Nacional. Los sucesos del día fueron extraordinarios por su dramatismo y por el liderazgo femenino. "Las mujeres de San Salvador, decía una nota periodística publicada en Costa Rica, "en pacífica manifestación, llegaron al Palacio Nacional y en la puerta fueron apaleadas" ("Los sangrientos sucesos de San Salvador", p. 4). Las bravas mujeres que lograron entrar al edificio llevaban banderas federales para indicar su apoyo al unionismo. Al llegar al Salón Azul, donde estaba reunida la Asamblea Nacional, con gritos y amenazas obligaron a los diputados a suspender el decreto de desmonetización.

Un grupo de mujeres de Santa Tecla respondió a la convocatoria de las señoras del mercado, pero 
al llegar a la capital el ejército las detuvo con disparos. La líder de este grupo cayó abatida a balazos. El heroísmo de las manifestantes y la crueldad de la represión inspiraron a estudiantes universitarios y de escuelas secundarias para unirse a la marcha. Las piedras sueltas de la calle eran su única arma defensiva ante las fuerzas del gobierno y las utilizaron sin titubeos. Por lo menos diez policías murieron apedreados. La multitud era tan intimidante que muchos policías cambiaron sus uniformes por ropa de civil y corrieron despavoridos. Se desconoce el número total de víctimas civiles de la jornada, se habla de al menos dieciséis muertos $y$, posiblemente, más. Sabemos que entre los fallecidos se incluían varias mujeres. Una de las principales líderes de las vendedoras del mercado, quizás la principal, era doña Concepción Cornejo de Figeac, que también estaba activa en el movimiento unionista ("Los sangrientos sucesos de San Salvador”, p. 4 y Figeac, 1947, p. 123).

A raíz de los motines de febrero el gobierno decretó el estado de sitio y llevó a cabo represión a gran escala. En medio de un ambiente de crispaciones políticas y penurias económicas el proyecto de la Federación continuaba. Guatemala, El Salvador y Honduras ratificaron el Pacto de Unión, no así Nicaragua, que nunca firmó, ni Costa Rica, donde, a última hora, la ratificación fracasó, al no contar con suficientes votos en la legislatura. Los tres países ratificantes nombraron diputados para una Asamblea Constituyente que comenzó sus sesiones en el Teatro Nacional de Tegucigalpa el 20 de julio.

Las reuniones de la Asamblea eran multitudinarias. El teatro se abarrotaba de gente que quería escuchar los argumentos de los diputados. Dado el papel que habían jugado las mujeres en toda Centroamérica para apoyar la unión no es de extrañar que el primer proyecto de constitución incluyera el tema del sufragio femenino. Las mujeres habían sido un apoyo importante para el frágil proyecto de unión el cual tenía grandes enemigos dentro y fuera de la región.

La discusión del sufragio femenino despertó pasiones. Un reportaje en el Diario del Salvador describe cómo el día en que se discutió este tema el público llenaba los corredores y galerías del teatro para hacer barra a sus oradores favoritos. ${ }^{28}$ Había muchos que se oponían a la idea. Uno de los delegados por Guatemala, José Astúa Aguilar, se opuso diciendo que las damas sufragistas "eran muy feas" idea que atribuyó a "pensadores ingleses" para darle legitimidad. ${ }^{29} \mathrm{Su}$ intervención recibió tantas críticas que tuvo que retractarse. Miguel Navarro, de Honduras, dijo que "Para 
las mujeres que fuman puro, ipara esas, señores, será el voto! El derecho que pretendemos otorgar ahora a la mujer es ridículo y criminal”. Pero había otras intervenciones más ilustradas. Otro hondureño, Ricardo Alduvín, argumentó que "por muy mal que desarrolle sus funciones políticas [la mujer] nunca lo hará tan mal como los hombres de Centroamérica. Que una mujer, por ladrona que sea, no podrá robar tanto como han robado nuestros Administradores de Rentas”. La barra en la galería recibió sus palabras con estruendosos aplausos y pidió que siguiera. "Habrá de seguro más nobleza política en cualquiera de nuestras mujeres, que en un diputado que pide para votar instrucciones al Presidente de la República o vende su voto a compañías extranjeras" continuó Alduvín. Para concluir señaló que él había "contemplado en Santa Ana, El Salvador, un formidable movimiento político unionista encabezado por un gran número de mujeres. Ellas tienen en las luchas políticas algo que casi siempre carecemos los hombres: patriotismo y serenidad."

El diputado por El Salvador, doctor Castro Ramírez, ofreció argumentos muy mesurados a favor del sufragio femenino. Su posición era que "la igualdad jurídica de los sexos, que descansa en igualdad de capacidad, autoriza para hacer esa concesión Qué tiene su fundamento en la tendencia moderna de dar participio en la vida colectiva a quienes son elementos de progreso y de adelanto en la sociedad, cómo que son la fuente de la vida, no sólo en su aspecto material, sino en todas las demás altas manifestaciones del espíritu humano". ("Lo que dijo el diputado Dr Castro Ramírez al defender en la Constituyente el voto femenino", p. 1).

Otro diputado salvadoreño, Eduardo Álvarez, usó el siguiente argumento: "Todo centroamericano reconoce el espíritu de trabajo de nuestra mujer; todos saben de su modestia y de su honradez sin tacha... ¿Por qué no darle el derecho de sufragio? ¿Por qué no darle el derecho de participar en la obra del Estado? Señores: lo único bueno que queda en Centro América es la mujer, salvemos nuestra obra de reconstrucción centroamericana engrandeciendo a la mujer para que sea la mejor sostenedora de nuestros trabajos". (Citado en Ticas, 2009).

Los argumentos sobre la pertinencia de incluir el sufragio femenino en la Constitución Federal rebasaban los salones del Teatro Nacional de Tegucigalpa. Los periódicos salvadoreños terciaban con columnas de opinión e inclusive con humor gráfico. La caricatura en la Figura 3 presenta al sufragio femenino como una amenaza para los hombres que terminan emasculados por mujeres que han ganado poder en el hogar. Una de las ideas que se repetía con frecuencia 
era que el derecho al voto introducía un elemento disociador en la familia tradicional.

FIGURA 3

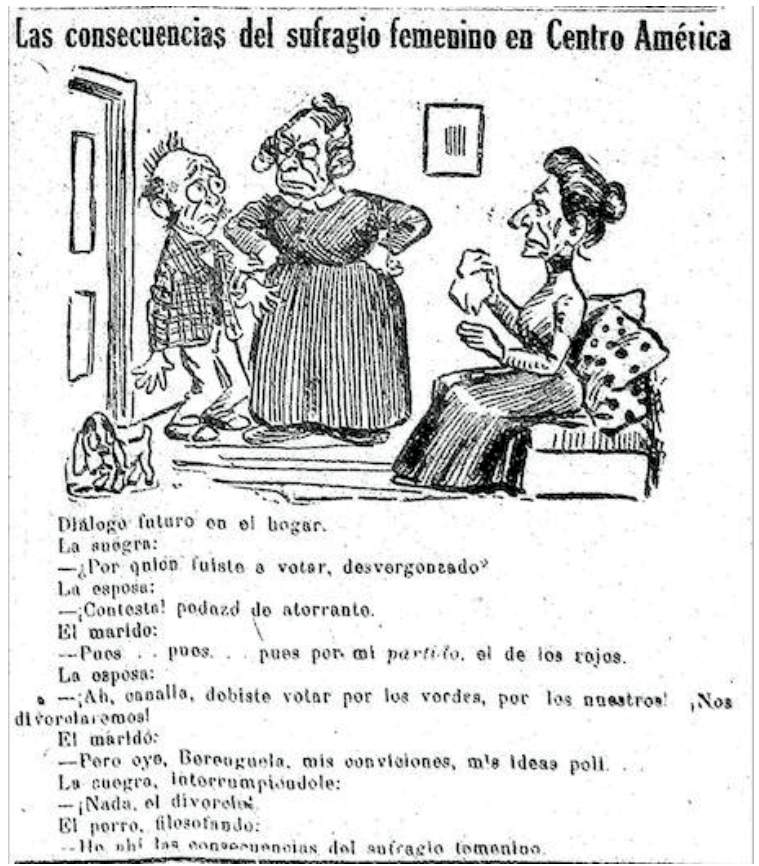

Las posiciones a favor del sufragio también estaban presentes en la prensa. El Diario del Salvador invitó a la veterana feminista Olimpia a dar su opinión sobre el tema. En su artículo ella demostraba con creces que había seguido informándose sobre las experiencias en otros países del mundo, hablaba de los beneficios que se habían dado en los lugares donde se permitía el voto femenino y además respondía a quienes sostenían que las mujeres no estaban listas para la ciudadanía:
"Nosotras preguntamos, cuando se le otorgó [el derecho al voto] al hombre ¿estaba suficientemente preparado? [...] Comprendemos que la mayor parte de los hombres adversarán nuestra causa y que muchos, desconociendo la dignidad que encierra, serán hostiles y tratarán de ridiculizarla, pero esto no demostrará más que la impotencia para defender sus opiniones". ("El sufragio femenino en Centroamérica. A la Asamblea Constituyente Federal", p. 5). 
La Constitución Política de la República Federal de Centroamérica estuvo lista para el 15 de septiembre. Su aprobación representaba la forma más significativa de conmemorar el centenario de la independencia. El artículo 29 de la nueva Carta Magna decía: "Podrán ejercer el derecho de sufragio las mujeres casadas o viudas mayores de 21 años, que sepan leer y escribir; las solteras mayores de 25 que acrediten haber recibido la instrucción primaria, y las que posean capital o renta en la cuantía que la Ley Electoral indique." Como dice Patricia Fumero en un trabajo pionero sobre el tema, con la aprobación de este artículo los diputados "reconocieron el decisivo papel político de las mujeres y su papel en la esfera pública de Centroamérica" 2005, p. 207).

La observación de Fumero contradice lo que dijeron algunos legisladores durante la discusión en la Asamblea Constituyente de
Tegucigalpa. Para diputados como el hondureño Miguel Navarro, otorgar el voto a las mujeres era una concesión que hacían los hombres, pues, a excepción de "tres o cuatro débiles solicitudes de agrupaciones", ellas realmente no lo pedían y, por el contrario, lo rechazaban ("En la Asamblea Constituyente Federal. Discusión sobre el voto femenino", p. 6). El activismo de mujeres unionistas como Prudencia Alfaro desmiente vigorosamente las aserciones de Navarro. El resumen de asociaciones de mujeres que se mencionan anteriormente en este texto (ver Cuadro 1) muestra con claridad que a partir de 1917, e incluso antes, en todas las esquinas del país ellas comenzaron a organizarse de forma acelerada para incidir en las decisiones políticas. Hay que tener en cuenta, además, que esta lista es muy parcial. No sabemos cuántos periodistas consideraron que la formación de una organización femenina no era noticia que mereciera espacio en su publicación.

Tabla 1. Resumen de asociaciones de mujeres mencionadas en el texto

\begin{tabular}{|c|c|c|c|}
\hline \multicolumn{2}{|c|}{ Asociaciones unionistas } & \multicolumn{2}{c|}{ Otras asociaciones } \\
\hline Nombre & $\begin{array}{l}\text { Primera } \\
\text { mención encon- } \\
\text { trada }\end{array}$ & Nombre & $\begin{array}{l}\text { Primera } \\
\text { mención encon- } \\
\text { trada }\end{array}$ \\
\hline $\begin{array}{l}\text { Club } \\
\text { Unionista } \\
\begin{array}{l}\text { Femenino, } \\
\text { Ahuachapán }\end{array}\end{array}$ & 1911 & $\begin{array}{l}\text { Club } \\
\text { Femenino }\end{array}$ & 1918 \\
\hline
\end{tabular}




\begin{tabular}{|c|c|c|c|}
\hline $\begin{array}{l}\text { Mengalas } \\
\text { Unionistas, } \\
\text { Ahuachapán }\end{array}$ & 1917 & $\begin{array}{l}\quad \text { Sociedad de } \\
\text { Costureras “El } \\
\text { Despertar" }\end{array}$ & 1920 \\
\hline $\begin{array}{l}\quad \text { Club } \\
\text { Unionista de } \\
\text { Señoritas Bellos } \\
\text { Horizontes", } \\
\text { Guazapa }\end{array}$ & 1917 & $\begin{array}{l}\quad \text { Sociedad } \\
\text { Femenil “El } \\
\text { Porvenir de la } \\
\text { Mujer" }\end{array}$ & 1921 \\
\hline \begin{tabular}{l}
\multicolumn{1}{c}{ Comité } \\
Unionista de \\
Señoras y \\
Señoritas de \\
Ahuachapán
\end{tabular} & 1917 & & \\
\hline $\begin{array}{l}\text { Comité } \\
\text { Unionista de San } \\
\text { Pedro Puxtla }\end{array}$ & 1917 & & \\
\hline $\begin{array}{l}\quad \text { Comité } \\
\text { Unionista de } \\
\text { Señoras de } \\
\text { Sonsonate }\end{array}$ & 1921 & & \\
\hline \begin{tabular}{l}
\multicolumn{1}{c}{ Comité } \\
Unionista \\
Femenino de \\
Quezaltepeque
\end{tabular} & 1921 & & \\
\hline $\begin{array}{l}\text { Comité } \\
\text { Femenino } \\
\text { Unionista de San } \\
\text { Salvador }\end{array}$ & 1921 & & \\
\hline \begin{tabular}{l}
\multicolumn{1}{c}{ Comité } \\
Femenino \\
Unionista de \\
Santa Ana
\end{tabular} & 1921 & & \\
\hline
\end{tabular}

Los gobiernos de El Salvador, fuera de forma parcial, la República Guatemala y Honduras ratificaron Federal. El siguiente paso después de la Constitución Federal, de forma ratificarlaConstitución era elegira las que por unos meses del año del autoridades ejecutivas y legislativas centenario volvió a existir, aunque del nuevo gobierno federal. En El 
Salvador se organizaron de forma apresurada unas elecciones que se llevaron a cabo a finales de octubre y principios de noviembre. En las semanas precedentes los periódicos y las autoridades debatieron si ante la ausencia de una ley electoral federal podían votar las mujeres ("Las próximas elecciones federales. El voto de las mujeres", p. 1).

La nueva Constitución decía con claridad que las mujeres podían votar. Por otro lado, ante la ausencia de una ley electoral a nivel federal se podía suponer que regía la salvadoreña que no decía nada sobre el sufragio femenino, aunque no lo prohibía. La discusión continuó hasta el último momento. Como la Ley Reglamentaria de Elecciones daba a las autoridades municipales la responsabilidad de llevar el registro de ciudadanos, un columnista del Diario del Salvador instó a las mujeres a que se registraran en las alcaldías como ciudadanas: "Cuanto antes, acudan de prisa y corriendo a las alcaldías, a inscribirse como ciudadanas, en los libros respectivos, pero esto, antes del último del mes en curso, para que puedan votar autoridades federales" ("La calificación ciudadana de la mujer ", p. 4). ${ }^{30}$

El llamamiento para elecciones federales se hizo tan cerca de la fecha de los comicios que no había habido tiempo para identificar candidatos de consenso. Los unionistas no confiaban en los candidatos que quería promover el gobierno y querían promover a sus candidatos. Como había mucho por coordinar, el Partido Unionista organizó precipitadamente una convención en Santa Ana para discutir su estrategia. Solamente faltaba una semana para las elecciones y seguía abierto el tema del voto femenino. Francisco Martínez Suárez, candidato para el Consejo Federal, hizo una moción para que la convención declarara su posición al respecto. La situación fue tensa. La señorita Carlota Herrera Otondo, que presidía la sesión, se veía en problemas para mantener el orden durante las acaloradas intervenciones. Un público numeroso llenaba el local. Abogados prominentes aseguraron que era posible que votaran las mujeres "para ello sólo se necesita que la mujer pase al municipio a inscribirse si es que reúne las condiciones prescritas por la ley" ("La sesión de clausura”, p. 4).

Los periódicos no cubrieron los comicios, posiblemente porque el gobierno de Jorge Meléndez, que mantenía una fuerte censura de prensa desde los motines de febrero, era hostil a los unionistas que incluían a los grupos más progresistas del país. Pero las salvadoreñas votaron. En 1921 muchas mujeres en El Salvador acudieron a las municipalidades a registrarse como ciudadanas y acudieron a las urnas. 
La prueba de que votaron se encuentra en un artículo firmado con el seudónimo de Floriano en un periódico que era parte de la propaganda política previa a las elecciones presidenciales de $1923 .{ }^{11}$
Lo publicaban los partidarios del Dr. Alfonso Quiñónez, uno de los candidatos. Floriano hacía historia de los comicios de 1921. Refiriéndose a la Constitución Federal, decía:

\section{"En virtud de la Ley citada un gran número de mujeres del país}

se inscribieron en los Registros de ciudadanos de las Alcaldías Municipales, para ejercer el sufragio y ya inscritas, en las elecciones del mes de noviembre del año próximo pasado [1921], concurrieron en el mayor orden y compostura y eligieron a los Diputados Federales del Estado con toda libertad, votando por los candidatos de su agrado y, quedando ya sentada, esa foja de servicios políticos de las mujeres salvadoreñas."

\section{Epílogo}

Las elecciones no garantizaban el éxito del proyecto unionista. Los obstáculos saltaban a la vista. La nueva Federación contaba con todo tipo de enemigos y enfrentaba sospechas. Para empezar, los gobernantes salvadoreños temían la pérdida de poder y tenían incertidumbre sobre el papel que les correspondería en una nueva estructura política. En Guatemala, el gobierno prounionista se encontraba bajo la amenaza de una oposición poderosa. Estados Unidos mostraba poco entusiasmo por el proyecto, pues creaba dificultades para ejercer hegemonía sobre la región. Por este motivo, los unionistas continuaron haciendo demostraciones de fuerza para impresionar a las autoridades en San Salvador.
El contingente femenino hizo su parte para apoyar a la nueva Federación con actos propagandísticos. Una semana después de los comicios, se organizó un nuevo Comité Femenino Unionista en San Salvador con Victoria Magaña de Fortín al frente. Una de las secretarias era Ana María Bonilla, de la Sociedad de Costureras "El Despertar". Sesenta señoras y señoritas firmaron el acta de fundación en un solemne acto en los salones de la Confederación de Obreros de El Salvador ("Comité unionista de señoras y señoritas", p. 4). El flamante comité capitalino tuvo un papel protagónico dos semanas más tarde durante la apoteósica visita del Comité Femenino Unionista de Santa Ana. El 21 de noviembre llegó a la estación de occidente el tren de las santanecas 
quienes traían un pabellón federal para entregarlo al comité de San Salvador. Durante su recorrido por la Avenida Independencia estuvieron rodeadas por "las banderas federales que portaban los diferentes comités unionistas femeninos" ("El recibimiento de la comisión de señoras unionistas y delegación de la junta directora del Partido Unionista de Santa Ana", p. 1).

La ceremonia de entrega del pabellón federal estaba programada para las 8:00 de la noche en el Teatro Principal. La afluencia de público fue tal que hubo que trasladar el programa al parque Bolívar. El reportaje del Diario del Salvador destacaba qué entre la audiencia se encontraban damas y señoritas de la aristocracia, mengalas y mujeres del pueblo ("Movimiento femenino unionista en El Salvador. Delegación femenina de Santa Ana", p. 2).

Las directivas de los respectivos comités se colocaron frente al Palacio Nacional para escuchar, en medio de grandes aplausos y vivas, los discursos de Doña Rosaura de Rivas Vides, la señorita Carlota Herrera Otondo y otras. La Prensa, que era el más unionista de los periódicos del país, le dio gran cobertura a la visita de las santanecas.

Al día siguiente el grupo de Santa Ana se dirigió al mercado. Al llegar las unionistas recibieron una cálida bienvenida llena de aplausos y aclamaciones. El discurso principal estuvo a cargo de la indudable líder de las señoras del mercado, la señora Concepción Cornejo de Figeac, que pronunció "un fogoso discurso lleno de entusiasmo, expresando el sentimiento popular y la firme decisión que todo el mercado tiene de secundar los esfuerzos de las mujeres de Santa Ana" ("Hoy en el mercado", p. 1).

Así tenemos que la causa del unionismo reunía en el mismo evento a la mujer que había sido líder de los motines de febrero y a las damas más encopetadas de la región cafetalera. Esa noche las señoras del mercado obsequiaron a las unionistas santanecas con un concierto que incluyó arias de Verdi y piezas de fox-trot. ("Por todas partes el aura popular se levanta en torno de las gentiles musas de la Federación Centroamericana”, p. 1).

Entre las instituciones que desconfiaban del proyecto de unión se encontraban las autoridades del catolicismo que habían intentado que la Constitución Federal colocara a su Iglesia en una posición privilegiada y no lo habían logrado. Cuando algunos sacerdotes utilizaron el púlpito para criticar la nueva Federación, las señoras del comité de San Salvador no dudaron en dirigirse al obispo y protestar en una carta abierta. El escrito era una forma sutil además de refutar la vieja idea liberal de que las mujeres 
eran marionetas de la Iglesia. La carta firmada por doña Victoria de Fortín, dirigida al Arzobispo de San Salvador, Monseñor Pérez y Aguilar, utiliza un tono muy diplomático pero firme destacando que "la mujer salvadoreña, en cuyo espíritu arde el fuego del sincero patriotismo no ha podido mostrarse indiferente en esta hora de resurgimiento de la Patria Grande", y luego se quejaba de que algunos sacerdotes "trabajen hoy decididamente contra la Unión, adversando la Carta Fundamental, qué es la base sobre qué descansa aquella" ("El Comité Unionista Femenino se dirige con una solicitud a los prelados de El Salvador y Honduras", p. 8). ${ }^{32}$

La defensa que hizo doña Victoria de la Constitución Federal llegó en momentos en que el proyecto de unión estaba naufragando. El gobierno de Carlos Herrera, que había sido pilar fundamental del Pacto de Unión, se había estado tambaleando todo el año. Su caída con el golpe de Estado del 5 de diciembre puso en marcha el fin de la Federación.

Estos eventos sirven de antecedente para evaluar la validez del artículo de Floriano que menciona que las mujeres realmente votaron durante las elecciones federales de finales de octubre de 1921. Para finales de 1922 el Pacto de Unión y la Constitución Federal eran papel mojado. Había llegado el momento de escoger un nuevo presidente de la República de El Salvador. La publicación donde apareció el artículo, El 29 de Agosto. Periódico Político, era uno de varios órganos de propaganda durante la furiosa competencia entre el candidato oficialista Alfonso Quiñónez y su opositor Miguel Tomás Molina. Este último era favorito de los unionistas puesto que había firmado el Pacto de Unión por parte de El Salvador. La presencia del artículo en el material de campaña de Quiñónez refuerza su credibilidad. Los quiñonistas eran hostiles a quienes habían apoyado al unionismo y durante la campaña política atacaron físicamente a las mujeres organizadas. A finales de noviembre de 1922, la Liga Roja, el grupo de choque de la campaña de Quiñónes, atacó a golpes a unas mujeres de Izalco que apoyaban la candidatura de Molina. Peor todavía fue el comportamiento de la Liga unas semanas más tarde, cuando protagonizó la famosa masacre de Navidad en San Salvador. En esa ocasión, atacó con armas blancas y de fuego la manifestación de mujeres a favor de Molina dejando en la calle a numerosos muertos y heridos (Lindo-Fuentes, 2014).

La publicación de Floriano apareció entre los dos ataques a las partidarias de Molina. El artículo mencionaba la votación de 1921 como argumento para que las mujeres votaran nuevamente en las elecciones de 1923: 


\begin{abstract}
"Estando como están inscritos, esos ciudadanos, [las mujeres] en los Registros municipales o Cantonales, desde aquella época, sin que hasta la fecha se les haya cancelado su inscripción, creemos, que ellas tienen perfecto derecho para votar en las próximas elecciones de Supremos Poderes, pues habiendo adquirido por aquella Ley, el derecho político del sufragio y no ha habido una ley que ordene la cancelación de su inscripción de ciudadanas, ni ellas han renunciado espontáneamente ese derecho, y puesto que, los derechos adquiridos no pueden violarse o revocarse, ni por ley, ni por consentimiento expreso de las partes, esas ciudadanas inscritas, si quieren pueden votar en los próximos comicios electorales, toda vez que, el derecho del sufragio como la emancipación civil y la manumisión por Derecho Romano, habiéndose dado a los favorecidos, no puede quitárseles; salvo el caso en que concurrieren las causales del Art. 30 de la Ley citada." ("El voto electoral de las mujeres salvadoreñas", $p$. 3).
\end{abstract}

En circunstancias en que la Liga Roja estaba en abierta batalla con las mujeres unionistas, el artículo del quiñonista Floriano, abogando por el sufragio femenino, lo colocaba en posición que contradecía a sus correligionarios. Aunque ocultaba su identidad detrás de un seudónimo, en el San Salvador de la época era difícil mantener secretos. Floriano sabía que estaba defendiendo una causa poco popular en su partido y no podía inventar detalles sobre algo tan importante y conocido por todos como la votación del año anterior. Se puede afirmar que su artículo deja pocas dudas que las salvadoreñas votaron en 1921 y por lo tanto fueron las verdaderas pioneras del voto femenino en Latinoamérica.

\title{
Conclusiones
}

Podemos concluir en primer Hay quienes prefieren citar el caso lugar que hay suficiente prueba de mujeres que votaron en Yucatán documental para decir que las en 1923, o en Uruguay en 1927. Pero, salvadoreñas fueron las primeras aunque éstas fueron votaciones latinoamericanas en votar. Los legales, eran a nivel local (Alejandre trabajos estándar sobre esta temática indican que las ecuatorianas fueron las primeras latinoamericanas que ejercieron el derecho al sufragio, pero ellas lo hicieron en 1929 (Deere y León de Leal, 2014, p. 47). Ramírez y Torres Alonso, 2016, p. 73; Altman, 2018, p. 150). En 1921 las salvadoreñas votaron en elecciones federales al amparo de una Constitución ratificada y vigente. El hecho de que haya desaparecido la 
República Federal de Centroamérica no le quita validez al voto legal que emitieron las salvadoreñas.

Una segunda conclusión es que el feminismo temprano en $\mathrm{El}$ Salvador es un área de estudio potencialmente muy fructífera. El artículo 29 de la Constitución federal no fue un "regalo de los hombres", como decían algunos políticos de la época, fue un logro político de mujeres políticamente activas. No cabe duda sobre la visión estratégica y la capacidad de organización de las mujeres que, al haber trabajado denodadamente por la unión de Centroamérica, demostraron que eran una fuerza política que no se podía ignorar. En los equilibrios de poder de 1921, las mujeres demostraron que era conveniente tenerlas como aliadas. Así funciona la política, ellas inclinaron la balanza a su favor.

Llama la atención, por ejemplo, la existencia de alianzas estratégicas que trascendían las barreras ideológicas, raciales y de clase. Doña Concepción Cornejo de Figeac, agitadora de grupos subalternos durante los motines de febrero tenía poco en común con las santanecas de clase alta del Comité Unionista. Había enormes diferencias entre los salones donde departía Victoria Magaña de Fortín y los mesones donde se hospedaba Prudencia
Ayala. El mundo económico de la membresía del "Comité Unionista de Señoras y Señoritas de Ahuachapán" estaba a gran distancia del de las "Mengalas Unionistas en Ahuachapán". Necesitamos nuevas investigaciones para comprender cómo se producían estas coaliciones. Quisiéramos saber mucho más sobre las acciones de Petrona Villeda en 1894, sobre la Sociedad de Costureras "El Despertar"y su líder María Bonilla, sobre las mengalas que asistían a salones de conferencias, sobre Victoria Magaña de Fortín y Teresa Masferrer. El conocimiento limitado que tenemos de su desempeño político es suficiente para saber que el sufragio femenino no fue preocupación exclusiva de damas de las clases altas influenciadas por lo que ocurría en Inglaterra o Estados Unidos.

Más investigación sobre el feminismo temprano ayudaría a "atar cabos". Las investigaciones de Alvarenga, Vásquez Monzón, y Valdés Valle sobre el siglo XIX, las de Ticas, Henríquez Consalvi, Navas y Fumero para la segunda década del siglo $X X$, se apreciarán mejor cuando se llenen las lagunas existentes y se comprenda mejor el entorno social, político e intelectual en que se movían las protagonistas, hasta ahora invisibles, del feminismo temprano en El Salvador. 


\section{Referencias bibliográficas}

- "Actitud patriótica del comité de señoras y señoritas de Ahuachapán". (1 de octubre de 1917). Patria, 1.

- Alejandre Ramírez, G. L., y Torres Alonso, E. (2016). “El Primer Congreso Feminista de Yucatán 1916. El camino a la legislación del sufragio y reconocimiento de ciudadanía a las mujeres. Construcción y tropiezos. " Estudios Políticos (39), pp. 59-89.

- Altman, D. (2018). Citizenship and Contemporary Direct Democracy. London: Cambridge University Press.

- Alvarenga, P. (1998). "Auxiliary Forces in the Shaping of the Repressive System: El Salvador, 1880-1930." En Chomsky, A. y Lauria-Santiago, A. (Eds.) Identity and Struggle at the Margins of the Nation-State. Durham: Duke University Press, pp. 122-150.

- - 1996. Cultura y ética de la violencia: El Salvador, 1880-1932. San José: EDUCA.

- "Antonia Navarro". (15 de junio de 1896). El Porvenir de Centroamérica, p. 388.

- Arias Mora, D. (2018). “La gran guerra de las mujeres: El mundo en 1914 y los orígenes del feminismo costarricense." Revista de Historia (77).

- Ayala, P. (1925). Inmortal. Amores de Loca. San Salvador: Imprenta Arévalo.

- - (1928). Payaso literario en combate. San Salvador: Imprenta Arévalo.

- Barberena, S. I. (1912). Anuario Estadístico de 1912. San Salvador: Tipografía "La Unión".

- Bermúdez, A. (1917). El Salvador al vuelo; notas, impresiones y perfiles. República de El Salvador, América Central, 1917. San Salvador: Impr. Moisant Bank Note Co.

- Burgos Seguí, C. de. (1 de octubre de 1906). “La mujer ante la ley”, Repertorio del Diario del Salvador, p. 2014.

- Burgos Seguí, C. de. (1 de diciembre de 1906). "El Consejo internacional femenino". Repertorio del Diario del Salvador, p. 2183.

- “Campaña unionista. Una nota del comité de Ahuachapán”. (28 de julio de 1911). Diario del Salvador, p., 1.

- Cañas Dinarte,C.(2010). Historias de mujeres protagonistas de la Independencia (1811-1814): insurgencia, participación y lucha de las mujeres de la Intendencia 
de San Salvador por lograr la emancipación del Reino de Guatemala. San Salvador: ISDEMU.

- Cañas Dinarte, C. (21 de septiembre de 2018). "Ella fue la primera mujer universitaria de Centroamérica”. El Diario de Hoy.

- Cardona, J. (1921). Convención unionista de Santa Ana. Impresiones de El Salvador. San José: Imprenta Minerva.

- "Celebrando la firma del Pacto de Unión centroamericana”. (2 de febrero de 1921). Diario del Salvador, p. 4.

- “Comité Unionista de señoras y señoritas". (8 de noviembre de 1921). Diario del Salvador, p. 4.

- Comité Unionista de Señoras y Señoritas de Ahuachapán". (8 de octubre de 1917). Patria, p. 2.

- “Cómo celebró Quezaltepeque la firma de la Unión”. (2 de febrero de 1921) La Prensa, p. 3.

- Congreso Pedagógico Centroamericano (1894). Primer congreso pedagógico centroamericano y primera exposición escolar nacional: instalados en la ciudad de Guatemala en diciembre de 1893 bajo la protección de José María Reyna Barrios. Guatemala: Tipografía y Encuadernación Nacional.

- "Convención de sociedades Obreras" (18 de enero de 1921). Diario del Salvador, p. 2

- Deere, C. D., y León de Leal, M. (2014). Empowering Women: Land and Property Rights in Latin America. Pittsburgh: University of Pittsburgh Press.

- "Detalles de la convención del partido unionista celebrada en San Salvador el 5 de noviembre". (26 de noviembre de 1920). La Prensa, pp. 1, 5.

- Diario Oficial (19 de octubre de 1894), pp. 1175-1176.

- Diario Oficial. "Memoria de Instrucción Pública”, (20 de marzo de 1920), p. 482.

- "Días agostinos" (26 de julio de 1912). Diario del Salvador, p. 1.

- "Editorial". (13 de julio de 1894). Diario Oficial, p. 730.

- Ejército de El Salvador (1894).Boletín del Ejército; reseña de los acontecimientos principales acaecidos en Santa Ana durante el sitio que la invicta ciudad sufrió en la revolución del 29 de abril de 1894. San Salvador: Imprenta Nacional.

- "El Comité Unionista Femenino se dirige con una solicitud a los prelados de El Salvador y Honduras". (8 de diciembre de 1921). La Prensa, p. 8. 
- "El recibimiento de la comisión de señoras unionistas y delegación de la junta directora del Partido Unionista de Santa Ana". (21 de noviembre de 1921). La Prensa, p. 1.

- "El Triunfo de la revolución en Salvador". (15 de agosto de 1885). Revista Latinoamericana, p. 332.

- El Nuevo Tiempo. (7 de noviembre de 1918), p. 9283.

- "El patriotismo de la mujer salvadoreña". (3 de septiembre de 1917). La Prensa, p. 5.

- El Salvador. Ramo de Instrucción Pública (1914). Memoria de los actos del poder ejecutivo en el ramo de instrucción pública, 1913. San Salvador: Imprenta Meléndez.

- -. (1915). Memoria de los actos del poder ejecutivo en el ramo de instrucción pública, 1914. San Salvador: Imprenta Meléndez.

- - (1916). Memoria de los actos del poder ejecutivo en el ramo de instrucción pública, 1915. . San Salvador: Tipografía "La Unión".

- - - (1917). Memoria de los actos del poder ejecutivo en el ramo de instrucción pública, 1916. San Salvador: Imprenta Nacional.

- - (1918). Memoria de los actos del poder ejecutivo en el ramo de instrucción pública, 1917. San Salvador: Imprenta Meléndez.

- "El voto electoral de las mujeres salvadoreñas". (2 de diciembre de 1922). El 29 de Agosto. Periódico Político, p. 3.

- "En la Asamblea Constituyente Federal. Discusión sobre el voto femenino". (1 de septiembre de 1921). Diario del Salvador, p. 6

- “En la recepción de los delegados hondureños". (22 de octubre de 1917). Patria, p. 2.

- 'Estatutos de la Sociedad Femenil 'El Porvenir de la Mujer'. (18 de febrero de 1921). Diario Oficial, p. 265.

- Federación de Obreros de El Salvador (1924). Ya era tiempo; obreros, conoce a tus malos guías. San Salvador, Imp. Diario del Salvador, p. 43.

- Figeac, J. F. (1947). La libertad de imprenta en El Salvador. San Salvador: Universidad Autónoma de El Salvador.

- Flores Montalvo, M. J. (2013). "Del discurso a la política educativa dirigida a la mujer en El Salvador 1894-1924." En Historia de mujeres, mujeres de historia en El Salvador, de Viegas Guillem, J. (Ed.). San Salvador: Dirección Nacional de Investigaciones en Cultura y Arte. 
- Fonseca, P. S. (1910). Primer Anuario Estadístico de San Salvador. San Salvador: Imprenta Arévalo.

- Fonseca, P. S. (1915). Anuario Estadístico de la República de El Salvador Correspondiente a 1914. San Salvador: Imprenta Nacional.

- Fumero-Vargas, A. P. (2005). National identities in Central America in a comparative perspective: the modern public sphere and the celebration of centennial of Central American Independence September 15, 1921 (tesis doctoral). Universidad de Kansas.

- "Fundación de una sociedad de ahorros y protección mutua de jóvenes obreras". (10 de febrero de 1917). Diario del Salvador, p. 2.

- "Grandes manifestaciones unionistas en la heroica ciudad de Santa Ana". (19 de febrero de 1921). La Prensa, p. 1.

- "Gremios y corporaciones". (18 de enero de 1913 ) Diario del Salvador, p. 3.

- "Habla una señorita”. (12 de diciembre de 1911). Vox Populi, p. 1.

- Henríquez Consalvi, C. (2009). "Prudencia Ayala, hija de la centella." Revista Trasmallo (4).

- "Hoy en el mercado" (22 de noviembre de 1921). La Prensa, p. 1.

- "La calificación ciudadana de la mujer". (8 de octubre de 1921). Diario del Salvador, p. 4.

- "La convención en el Puerto de La Unión". (2 de noviembre de 1918). El Nuevo Tiempo, p. 9266.

- "La convención unionista de El Salvador". (9 de noviembre de 1918) El Nuevo Tiempo, p. 9290.

- “La imponente manifestación unionista de anoche”.(24 de febrero de 1921). La Prensa, p. 1.

- "La manifestación obrera en homenaje al doctor Araujo". (7 de febrero de 1916), La Prensa, p. 1

- "La mujer colaboradora, no esclava”. (17 de febrero de 1912). Diario del Salvador, p. 2

- "La mujer salvadoreña en la campaña unionista”. (2 de diciembre de 1920). La Prensa, p. 2.

- "La próxima convención unionista que se celebrará en la ciudad de Santa Ana”. (8 de febrero de 1921). Diario del Salvador, p. 4.

- "La sesión de clausura". (22 de octubre de 1921). La Prensa, p. 4. 
- "La simpática manifestación de las señoras del mercado. Entusiasta discurso de una señorita”. ( 17 de enero de 1913). Diario del Salvador, p. 1.

- "Labor de nuestro corresponsal en Quezaltepeque". (14 de febrero de 1921). La Prensa, p. 4.

- "Las heroínas de la revolución libertadora de Nicaragua". (28 de noviembre de 1912). Diario del Salvador, p. 2.

- "Las mujeres hacen municiones" (11 de abril de 1917). Diario del Salvador, p. 1.

- "Las obreras del mercado y los emigrados de Nicaragua". (1 de octubre de 1912). Diario del Salvador, pp. 2-4.

- "Las próximas elecciones federales. El voto de las mujeres". (3 de octubre de 1921). Diario del Salvador, p. 1.

- "Ley reglamentaria de elecciones".(21 de septiembre de 1886).Diario Oficial, p. 1049.

- Lindo-Fuentes, H. (2019). El alborotador de Centroamérica. San Salvador: UCA Editores-Colegio de Michoacán.

- -. (2014). La sangrienta Navidad de 1922: ataque a una manifestación de mujeres. 15 de diciembre. Disponible en: https://www.elfaro.net/ es/201412/academico/16344/La-sangrienta-Navidad-de-1922-ataque-auna-manifestación-de-mujeres.htm.

- Lionetti, L. (2006). La educación de las mujeres en América Latina: formadoras de ciudadanos. En de Morant, I. (Ed.). Historia de las mujeres en España y América Latina, vol. III, pp. 849-869. Madrid: Cátedra.

- López Vallecillos, I. (1964). El periodismo en El Salvador bosquejo histórico. San Salvador: Editorial Universitaria.

- "Los sangrientos sucesos de San Salvador". (19 de marzo de 1921). Diario de Costa Rica, p. 4.

- Magaña de Fortín, V. (1910). 1902. Importancia de la mujer. San Salvador: s/e.

- "Manifiesto de la convención del partido unionista de El Salvador a sus correligionarios". (26 de noviembre de 1920). La Prensa, p. 5.

- Masferrer C., T. (1911). Nociones de higiene al alcance del pueblo y para el uso de las familias y escuelas. San Salvador: Tipografía La Unión.

- Mendieta, Salvador. (1903). Páginas de Unión. Managua: Tipografía de J. C. Gurdián y Cía. 
- - (1910a). La enfermedad de Centroamérica. Vol. 1. Barcelona: Tipografía Maucci.

- -. (1910b). La enfermedad de Centroamérica. Vol. 2. Barcelona: Tipografía Maucci.

- -. (1934). La enfermedad de Centroamérica. Vol. 3. Barcelona: Tipografía Maucci.

- "Mensaje del señor presidente de la República del Salvador". (20 de febrero de 1904). Diario Oficial, p. 282.

- Merlos, S. R. (1921). Hacia la Unión. San Salvador: Tipografía La Vanguardia.

- Ministerio de Relaciones Exteriores (1911). "Memoria de los actos del ejecutivo en el ramo de relaciones exteriores." Boletín del Ministerio de Relaciones Exteriores (61).

- Moncada, I. (1907). El gobierno del Señor Don Pedro José Escalón. Reseña administrativa de los actos mas salientes de su periodo presidencial. San Salvador: Tipografía El Comercio.

- "Movimiento feminista salvadoreño. Se constituye la sociedad de mujeres trabajadoras". (21 de septiembre de 1920). La Prensa, p. 1.

- "Movimiento femenino unionista en El Salvador. Delegación femenina de Santa Ana". (22 de noviembre de 1921). Diario del Salvador, p. 2.

- Navas, M. C. (2012). Sufragismo y feminismo: visibilizando el protagonismo de las mujeres salvadoreñas. San Salvador: Editorial Universitaria.

- "No ha sido expulsada de la sociedad de tipógrafos la señorita Gutiérrez Muñoz". ( 21 de marzo de 1914), Diario del Salvador, p. 2.

- “Nuestro Centro de Enseñanza”. (Diciembre 1920-Agosto 1921). Ateneo de El Salvador, p. 1645.

- “Nuestros delegados". (19 de septiembre de 1917), Patria, p. 2

- "Oración pronunciada por el Sr. Inspector General de los establecimientos de beneficencia". (23 de septiembre de 1913). El Centroamericano, p. 3.

- "Por todas partes el aura popular se levanta entorno de las gentiles musas de la Federación Centroamericana”. ( 23 de noviembre de 1921). La Prensa, p 1.

- "Prudencia Ayala defiende una causa justa y noble, cual es el derecho de la mujer a ser elector y ocupar altos puestos”. (25 de julio de 1930). Patria, p. 1. 
- "Res non verba: esto exige el unionismo del momento". (24 de septiembre de 1920). La Prensa, p. 1.

- Rodríguez, E.(2006). "Movimientos de mujeres y feministas en América Central (1890-1965)." En: Morant, I. (Ed.). Historia de las Mujeres. España y América Latina. Pp., 553-575. Madrid: Ediciones Cátedra.

- "Solemne manifestación unionista en Chalchuapa". (2 de febrero de 1921). Diario del Salvador, p. 4.

- “Una capitana del ejército salvadoreño. Peleó valientemente en 1894” (12 de enero de 1912). Diario del Salvador, p. 1.

- Ticas, S. P. (2001). Historia, feminismo y literatura: Escritoras salvadoreñas, 1920-1960 (tesis doctoral). University of California, Berkeley.

- Ticas, S. P. (1 de enero de 2009). “El unionismo centroamericano y el sufragio femenino". El Faro.

- Vásquez Monzón, O. C. (2013).“La mujer religiosa, la mujer ilustrada, la mujer ciudadana: representaciones y prácticas femeninas en algunos periódicos salvadoreños, 1871-1889." Revista Realidad (135), pp. 5-34.

- Vásquez Monzón, O. y Tamayo-Acosta,J.J.(2014). Mujeres en público: el debate sobre la educación femenina entre 1871 y 1889. San Salvador: UCA Editores.

- Vázquez Monzón, O. (2011). “Sobre la instrucción intelectual de las mujeres en la prensa salvadoreña. Hechos y decires (1871-1887)”. Cultura (106), pp. 27-53.

- Valdés Valle, R. A. (2010). Masones, liberales y ultramontanos salvadoreños: debate político y constitucional en algunas publicaciones impresas, durante la etapa final del proceso de secularización del estado salvadoreño (1885-1886) (tesis doctoral). Universidad Centroamericana "José Simeón Cañas", San Salvador.

- "Vida Salvadoreña" (23 de enero de 1917). El Nuevo Tiempo, p. 7141.

\section{Notas}

1. Esta obra, junto con la recopilación más completa de obras, documentos, recortes y fotografías relacionadas con Prudencia Ayala se encuentra en el Museo de la Palabra y la Imagen.

2. Esta primera institución se transformó en el Colegio Nacional de Señoritas donde se le quitó el énfasis a su aspecto de institución especializada.

3. Esta discusión se dio alrededor del mismo tiempo en el resto de Centroamérica (Rodríguez, 2006).

4. El papel de las mujeres en las políticas sociales del Estado liberal los discute 
Eugenia Rodríguez (Rodríguez 2006, p. 562).

5. Un resumen de la actividad filantrópica de Sara de Zaldívar aparece en "Oración pronunciada por el Sr. Inspector General de los establecimientos de beneficencia", p. 3.

6. Para los antecedentes familiares de Navarro, ver Cañas Dinarte (2018).

7. En su artículo "Feminismo" hace un estudio comparativo del movimiento feminista en Europa (Magaña de Fortín 1910, p. 85).

8. Publicar un libro era todo un acontecimiento. El total de títulos que se publicó en 1914 fue de veintitrés (Fonseca, 1915).

9. Ver por ejemplo "Las mujeres hacen municiones”, p, 1. El artículo discute en gran detalle el impacto de la Primera Guerra Mundial en el movimiento feminista en Costa Rica(Arias Mora, 2018).

10. Es claro que en El Salvador las mujeres siempre participaron en el mundo laboral rural y en el trabajo artesanal. Para los propósitos de este artículo el grupo de mujeres trabajadoras a las que hay que prestar atención son las que su situación en zonas urbanas les permitía participar en los movimientos sociales de la época.

11. Para el contexto latinoamericano, ver Lionetti (2006).

12. Las escuelas normales para maestras fueron un poco inestables. La primera fue la Escuela Normal de Institutrices de 1874. Para 1881, se llamaba Colegio Normal de Señoritas. Además, los colegios de señoritas daban clases de bachillerato en ciencias y letras. Para más detalles sobre la evolución de las escuelas normales para maestras ver Vázquez Monzón (2011).

13. En 1910 la matrícula total de la institución incluía 182 alumnas de la ense- ñanza normal, 113 en la sección preparatoria.

14. Esta institución aparece por primera vez en la Ley de Presupuesto para 1904-1905 con el nombre de Escuela técnico-práctica de la mujer. Ver Diario Oficial, 30 de mayor de 1904, 295. La iniciativa de su fundación la tuvo del Dr. Nicolás Aguilar, encargado de la cartera de instrucción pública del gobierno del general Escalón. (Moncada 1907, 32)

15. Orantes fue fundadora de la revista $L a$ Escuela de El Salvador.

16. En el Diario del Salvador del 1 de febrero de 1917 , p. 2, aparece el anuncio comercial de la "Escuela de comercio para señoritas" fundada por Emilia Angulo. La noticia sobre la escuela de complementación aparece en "Información Salvadoreña”, El Nuevo Tiempo, 16 de febrero de 1917, 7220. Para la escuela anexa a la Froebel, ver El Salvador. Ramo de Instrucción Pública (1918, p. 372)

17. Para el número de asociaciones en 1921 ver Fumero-Vargas (2005, p. 66). Para una discusión más extensa de estas asociaciones ver Lindo-Fuentes (2019, pp. 11-19).

18. Este grupo aparece en la lista de organizaciones obreras que se encuentra en Bermúdez (1917, p.172).

19. En 1917 se dio un fenómeno similar de organización de mujeres unionistas en Honduras, Nicaragua y Costa Rica. Patria, el periódico unionista que se publicaba en Honduras, contiene numerosas referencias a estos grupos, particularmente los hondureños. Ver también FumeroVargas (2005, p. 50).

20. Parece que no han sobrevivido copias de Escible.

21. Publicado originalmente en el Diario de Occidente, Santa Ana, 28 de junio de 1918.

22. La presión popular se menciona en "Manifiesto de la convención del partido 
unionista de El Salvador a sus correligionarios", p, 5.

23. Sonia Ticas sugiere que Prudencia Ayala era principalmente autodidacta (Ticas 2001, cap. 2). Este capítulo del libro de Ticas ofrece un útil esbozo biográfico y análisis de sus escritos. Una de las principales fuentes de información sobre la vida de Prudencia Ayala es Henríquez Consalvi (2009).

24. Según el censo de 1950, solamente el $67.5 \%$ de los hombres urbanos y el $26.3 \%$ de las mujeres urbanas nacidos entre 1896 y 1905 estaban alfabetizados. (Lindo-Fuentes, 2019, p. 6).

25. La palabra mengala podía tener connotaciones despectivas, pero aparentemente se podía usar también de forma meramente descriptiva de una categoría social nueva.

26. La Prensa describió el primer día de la convención. Ver "Grandes manifestaciones unionistas en la heroica ciudad de Santa Ana", p. 1.

27. En una entrevista que le hizo el Diario del Salvador en diciembre de 1930, ella menciona que, cuando hizo la moción en el seno de la convención, fue recibida con la inmediata oposición de los señores representantes. El Museo de la Palabra y la Imagen tiene un recorte de periódico con la entrevista.
28. La descripción y las citas textuales que siguen se encuentran en: "En la Asamblea Constituyente Federal. Discusión sobre el voto femenino", p. 6.

29. Astúa Aguilar era un prominente abogado liberal costarricense exilado en Guatemala. La delegación guatemalteca incluía a un diputado más de otro país centroamericano, el nicaragüense y ferviente unionista Salvador Mendieta.

30. La Ley Reglamentaria de Elecciones vigente era la de 1886. En la sección sobre calificación de ciudadanos (Capítulo II) dice solamente "La calificación se hará por las respectivas municipalidades". "Ley Reglamentaria de Elecciones”, p. 1049.

31. Este artículo apareció en El 29 de Agosto. Periódico Político, 2 de diciembre de 1922, p. 3. Otros periódicos de los comités quiñonistas: Alma salvadoreña, órgano del subcomité de obreros quiñonistas del partido; El vencedor, órgano del comité departamental del Partido Nacional Democrático; El pueblo, órgano quincenal de propaganda a favor del Dr Alfonso Quiñones Molina; Opinión Obrera, periódico de propaganda política, órgano del Comité Central de obreros pro Quiñones

32. Aunque el titular menciona al prelado de Honduras, la carta no lo menciona. 